Article

\title{
Time-Dependent Afterslip of the 2009 Mw 6.3 Dachaidan Earthquake (China) and Viscosity beneath the Qaidam Basin Inferred from Postseismic Deformation Observations
}

\author{
Yang Liu ${ }^{1,2,3,4, *}$, Caijun $\mathrm{Xu}{ }^{1,2,3}$, Zhenhong Li ${ }^{4}$, Yangmao Wen ${ }^{1,2,3}$, Jiajun Chen ${ }^{4}$ and Zhicai Li ${ }^{5}$ \\ 1 School of Geodesy and Geomatics, Wuhan University, Wuhan 430079, China; cjxu@sgg.whu.edu.cn (C.X.); \\ ymwen@sgg.whu.edu.cn (Y.W.) \\ 2 Key Laboratory of Geospace Environment and Geodesy, Ministry of Education, Wuhan University, \\ Wuhan 430079, China \\ 3 Collaborative Innovation Center for Geospatial Technology, Wuhan 430079, China \\ 4 COMET, School of Civil Engineering and Geosciences, Newcastle University, \\ Newcastle upon Tyne NE1 7RU, UK; Zhenhong.Li@newcastle.ac.uk (Z.L.); J.Chen26@newcastle.ac.uk (J.C.) \\ 5 Department of Geodesy, National Geomatics Center of China, Beijing 100048, China; zcli@nsdi.gov.cn \\ * Correspondence: Yang.Liu@sgg.whu.edu.cn; Tel.: +86-27-6877-8404
}

Academic Editors: Roberto Tomas, Salvatore Stramondo and Prasad S. Thenkabail Received: 30 June 2016; Accepted: 3 August 2016; Published: 10 August 2016

\begin{abstract}
The 28 August 2009 Mw 6.3 Dachaidan (DCD) earthquake occurred at the Qaidam Basin's northern side. To explain its postseismic deformation time series, the method of modeling them with a combination model of afterslip and viscoelastic relaxation is improved to simultaneously assess the time-dependent afterslip and the viscosity. The coseismic slip model in the layered model is first inverted, showing a slip pattern close to that in the elastic half-space. The postseismic deformation time series can be explained by the combination model, with a total root mean square (RMS) misfit of $0.37 \mathrm{~cm}$. The preferred time-dependent afterslip mainly occurs at a depth from the surface to about $9.1 \mathrm{~km}$ underground and increases with time, indicating that afterslip will continue after 28 July 2010. By 334 days after the main shock, the moment released by the afterslip is $0.91 \times 10^{18} \mathrm{~N} \cdot \mathrm{m}$ (Mw 5.94), approximately $24.3 \%$ of that released by the coseismic slip. The preferred lower bound of the viscosity beneath the Qaidam Basin's northern side is $1 \times 10^{19} \mathrm{~Pa} \cdot \mathrm{s}$, close to that beneath its southern side. This result also indicates that the viscosity structure beneath the Tibet Plateau may vary laterally.
\end{abstract}

Keywords: afterslip; the 2009 Dachaidan earthquake; viscosity; the Qaidam Basin; postseismic deformation; InSAR

\section{Introduction}

On 28 August 2009, an Mw 6.3 earthquake occurred at the Dachaidan (DCD) district, Qinghai province in China [1-4]. About ten months before this event, another Mw 6.3 event occurred at almost the same location (Figure 1). The two events threaten human beings moderately. The related rupturing faults are part of the northern fold-and-thrust belts of the Qaidam Basin, which has a strike of northwestern-west (NWW) to southeastern-east (SEE) and divides the northeastern margin of the Tibet Plateau into the Qaidam block and the Qilianshan block [5,6]. This zone has the tectonic characteristics of significant uplift in the geologic history $[5,6]$. However, because of the complex topography and the arduous working environment, the related observations and explanations are not yet sufficient, in particular for the zone around this event. Previous studies suggested that the occurrence of earthquake can present an opportunity to explore the earthquake behaviors and rheological properties of the regional lithosphere materials [7-18]. 
Geodetic observations of surface deformation related to the active fault can be used to characterize the behaviors of the earthquake cycle [19]. During the interseismic phase, Global Positioning System (GPS) observations of crustal strain within the Tibet Plateau suggested that the fault belts around the 2009 event are characterized by the thrust movement along vertical direction and the left-lateral movement along horizontal direction [20]. During the coseismic phase, Interferometric Synthetic Aperture Radar (InSAR) observations of surface deformation and the elastic dislocation model inversion using both uniform and distributed slip models indicated that the 2008 event ruptured the lower half of the brittle seismogenic layer, while the 2009 event ruptured the upper half $[1,3,21]$. During the postseismic phase, InSAR deformation time series for the first 334 days after the 2009 event displayed that the postseismic deformation changes from fast to slow with time, and has a similar spatial pattern with the coseismic deformation [22,23]. On the geophysical interpretation of the postseismic deformation, Feng [22] modeled it using the postseismic afterslip model only.

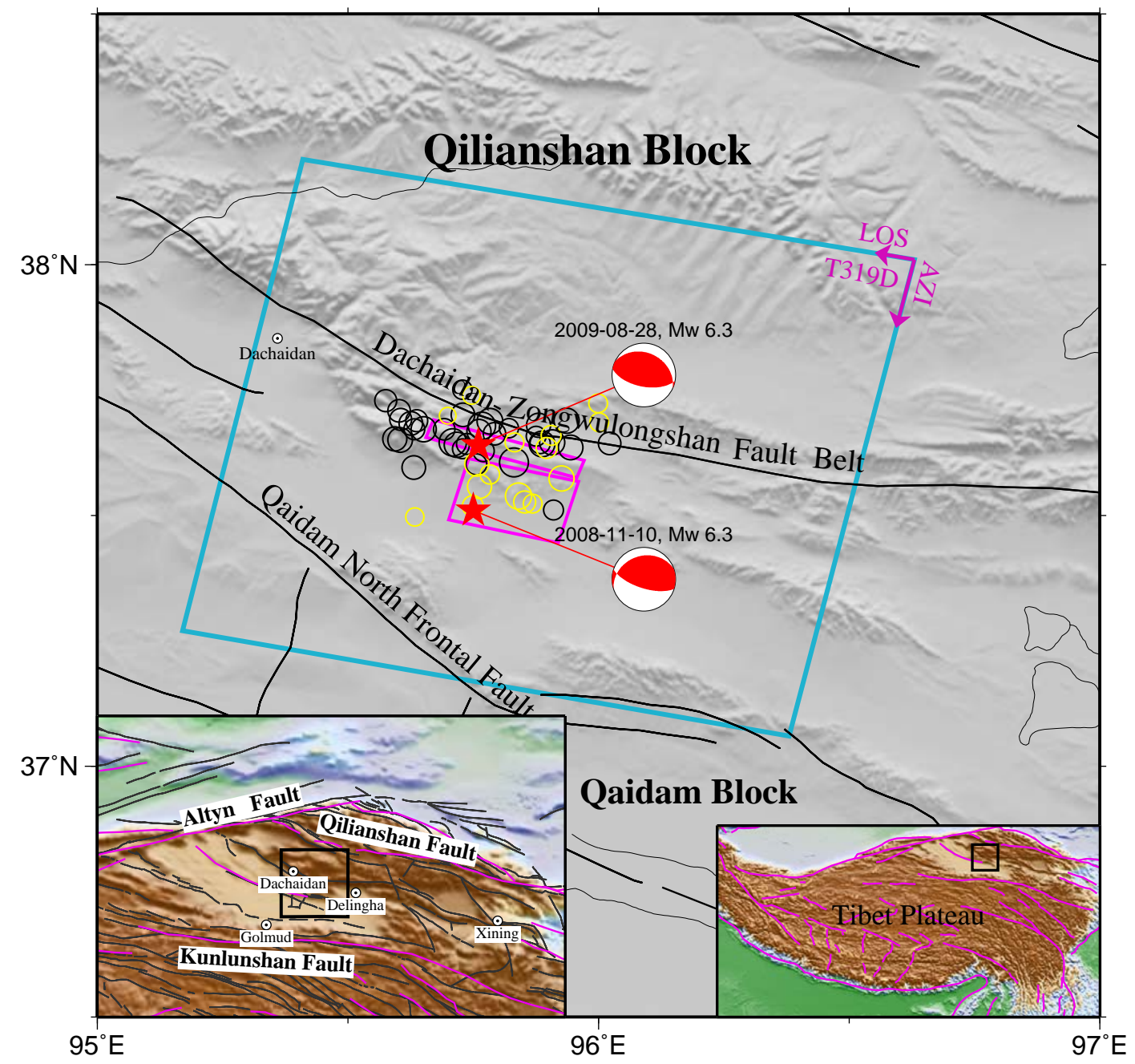

Figure 1. Tectonics associated with the 2009 Mw 6.3 DCD earthquake. The bottom-left and bottom-right insets show the location of the main figure, respectively. The light blue rectangle is the spatial extent of the Envisat Advanced Synthetic Aperture Radar (ASAR) descending Track 319 images, with AZI and LOS referring to satellite azimuth and look directions. The focal mechanisms of the 2008 and 2009 events are from United States Geological Survey (USGS) [4]. The two purple rectangles are the surface projections of the main fault rupturing zones during the 2008 and 2009 events $[3,21]$. The black and yellow hollow circles are the aftershocks of the 2008 and 2009 events, respectively [4]. The purple and black lines are the active faults from Peltzer and Saucier [24] and Deng et al. [5], respectively. 
Three postseismic deformation mechanisms, alone or mixed, have been proposed to interpret the observed movements after an earthquake event, including poroelastic rebound, afterslip, and viscoelastic relaxation. InSAR observations have been successfully used to constrain the possible geophysical mechanisms of some earthquake cases [15,16,25-32]. The mechanism of poroelastic rebound usually influences the postseismic deformation within a few kilometers to fault ruptures in a short period of time, whereas the other two mechanisms can generate postseismic deformation with a similar spatial pattern in the first few years [11,33]. However, the relative significance of the viscoelastic relaxation always increases with time, and the afterslip is usually contrary with it $[11,16]$. With these results, in this study we will interpret the observed postseismic deformation time series of the 2009 Mw 6.3 DCD earthquake with the combination model of afterslip and viscoelastic relaxation, along with comparisons of afterslips derived from the pure afterslip and the combination models.

Slip models are essential for interpreting postseismic deformation with the model of viscoelastic relaxation and the combination model of afterslip and viscoelastic relaxation [11,28,32]. When modeling with the combination model, previous studies usually considered the viscoelastic relaxation due to coseismic slip only, and neglected that due to the accumulated afterslip [16,28-30,32]. Recent study by Diao et al. [33] adopted a method which can consider the viscoelastic relaxation due to coseismic slip and the accumulated afterslip. In Diao et al. [33], coseismic slip and the accumulated afterslip estimated by pure afterslip model were directly employed as the driving force sources of viscoelastic relaxation. This means that Diao et al. [33] assessed afterslip and viscoelastic relaxation separately, first the afterslip and then the viscoelastic relaxation. With such a processing method, the input accumulated afterslip model may be not very reasonable because the afterslip and the viscoelastic relaxation processes are interactional during the postseismic phase. Therefore, it is necessary to carry out researches on simultaneously estimating the afterslip and viscoelastic relaxation parameter (viscosity).

In this study, we mainly focus on four items, including (1) improving the method in Diao et al. [33] to estimate the time-dependent afterslip distribution and the viscosity simultaneously; (2) modeling the InSAR deformation time series following the 2009 Mw 6.3 DCD earthquake in Liu et al. [23]; (3) seeking the dominant mechanisms responsible for postseismic deformation; and (4) finally investigating the viscosity beneath the northern side of the Qaidam Basin.

\section{Data and Layered Model}

\subsection{Data}

Investigating the postseismic deformation process requires the use of data from geodetic observations $[7,34]$. GPS data has been proven as an effective observation to accurately constrain the postseismic process due to its high horizontal precision and time resolution [35-37]. Unfortunately, for this event, according to Chen et al. [38], there are not enough GPS observations around the earthquake zone. The nearest station is approximately $40 \mathrm{~km}$ far away from the epicenter, making it unavailable to use GPS observation to do the following modeling. Meanwhile, InSAR data has also been confirmed as an alternative observation to investigate the postseismic process due to its high vertical precision and spatial resolution [15,16,25-32]. Feng [22] and Liu et al. [23] have derived the postseismic deformation time series. In this study, we prefer to use the observations from Liu et al. [23] because it includes one more SAR image than Feng [22], and has more observations in the near-field region.

The deformation time series in Liu et al. [23] are derived by processing the C-band Envisat ASAR descending Track 319 images with a small baseline subset InSAR technique, and include eight time epochs (Table 1). These epochs correspond to 19 days, 54 days, 124 days, 194 days, 229 days, 264 days, 299 days, and 334 days after the main shock, respectively. The derived InSAR deformation time series during the first 334 days after the event change from fast to slow with time, and display a smaller displacement for the footwall than that for the hanging wall, where the deformation decreases from the middle to both sides (Figure 2). 


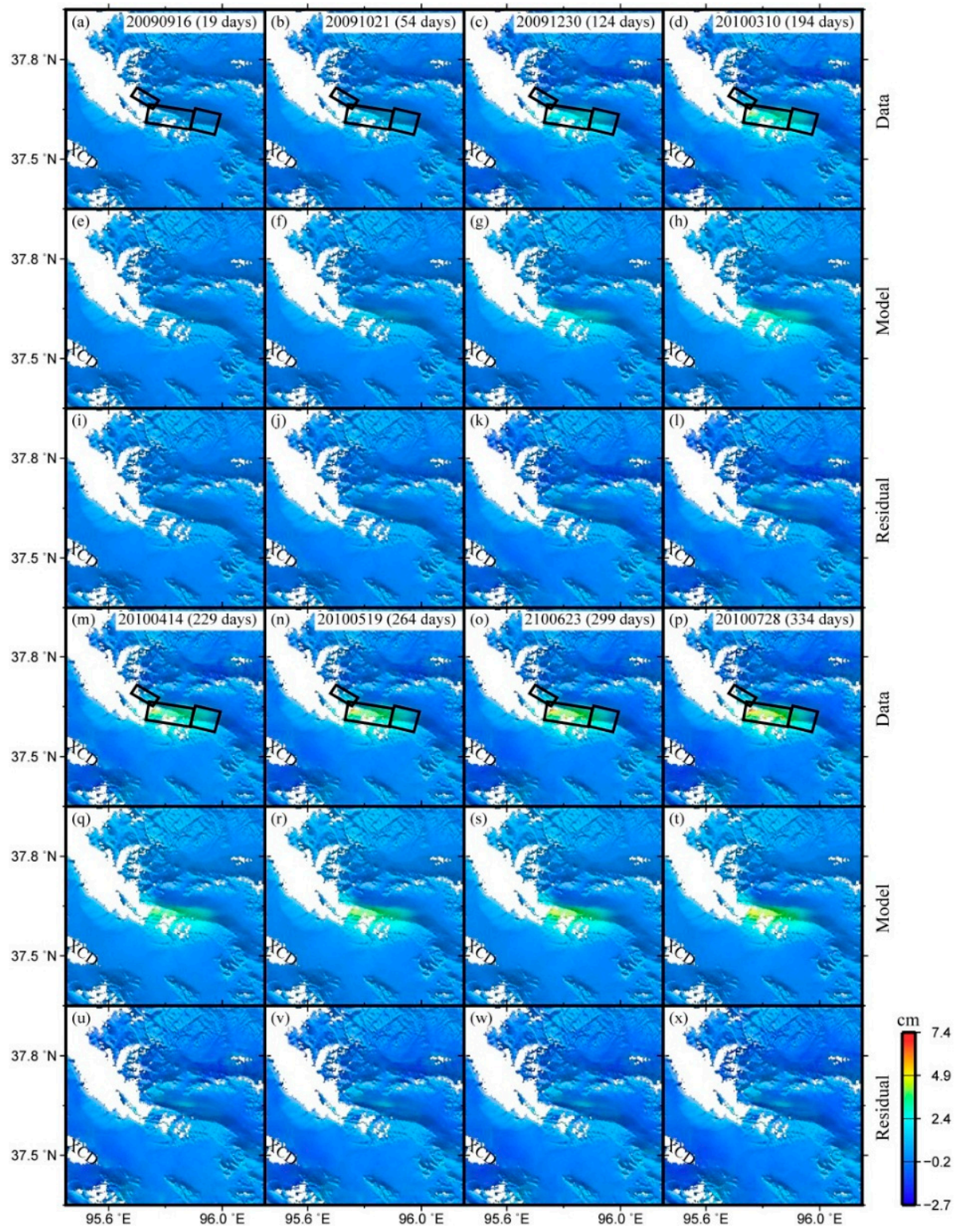

Figure 2. (a-d) Observed postseismic deformation time series at the first four time epochs of InSAR observations [23]; (e-h) modeled postseismic deformation time series from the combination model of afterslip and viscoelastic relaxation; and (i-1) residual deformation time series by subtracting (e-h) from $(\mathbf{a}-\mathbf{d}) ;(\mathbf{m}-\mathbf{x})$ are for the last four time epochs of InSAR observations [23]. The dates and days after the $2009 \mathrm{Mw}$ 6.3 DCD earthquake are labeled at the top-right of subfigures $(\mathbf{a}-\mathbf{d})$ and $(\mathbf{m}-\mathbf{p})$. XCD is the abbreviated form of Xiaochaidan. Positive and negative values indicate motions toward and away from the satellite in the line-of-sight (LOS) direction, respectively.

According to Liu et al. [23], the spatial pattern of the postseismic deformation is similar with that of the coseismic deformation. This may indicate that an underground fault is processing during the postseismic phase similar to that during the coseismic phase. In other words, postseismic afterslip may occur with similar fault geometry and slip distribution as coseismic slip. Meanwhile, the correlation coefficient of 0.73 indicates that the postseismic afterslip may have a different slip distribution, and/or that the other types of postseismic deformation mechanisms may occur. After analyzing the three mechanisms described above, in this study mechanisms of afterslip and viscoelastic relaxation are considered, and their behaviors will be investigated by the modeling experiments in the following content. 
Table 1. Observation data used in this study.

\begin{tabular}{|c|c|c|c|c|c|c|}
\hline Date No. & Date & $\mathrm{T}^{\mathrm{a}}$ (Days) & Alpha $^{b}(\mathbf{k m})$ & $\operatorname{Sigma}^{c}(\mathrm{~cm})$ & RMS $^{d}(\mathrm{~cm})$ & Statistic Value ${ }^{\mathrm{e}}(\mathrm{cm})$ \\
\hline 1 & 16 September 2009 & 19 & 4.72 & 0.07 & 0.07 & \multirow{8}{*}{$0.31 / 0.37$} \\
\hline 2 & 21 October 2009 & 54 & 4.72 & 0.20 & 0.19 & \\
\hline 3 & 30 December 2009 & 124 & 4.72 & 0.36 & 0.36 & \\
\hline 4 & 10 March 2010 & 194 & 4.24 & 0.36 & 0.40 & \\
\hline 5 & 14 April 2010 & 229 & 4.40 & 0.35 & 0.41 & \\
\hline 6 & 19 May 2010 & 264 & 4.84 & 0.34 & 0.42 & \\
\hline 7 & 23 June 2010 & 299 & 5.56 & 0.37 & 0.44 & \\
\hline 8 & 28 July 2010 & 334 & 6.12 & 0.46 & 0.47 & \\
\hline
\end{tabular}

\subsection{Layered Model}

It is well known that a layered model is needed to interpret the postseismic deformation with mechanisms related to viscoelastic relaxation [28-32]. In addition, the input coseismic slip, which is considered as a driving force source of viscoelastic relaxation, should also be obtained in the layered model. Previous studies using seismic wave data have constructed some layered models.

An et al. [40] adopted records from 27 fundamental stations located in China and three stations located in Islamabad (Pakistan), Kabul (Afghanistan), and New Delhi (India) to image the 3-D shear velocity structure in Northwestern China. According to An et al. [40], the Qaidam Basin zone has an average $\mathrm{S}$ wave velocity of about $3.55 \mathrm{~km} / \mathrm{s}$ in the 56-kilometer-thick crust and can be divided into four structural layers: the first one has an $S$ wave velocity of $3.00 \mathrm{~km} / \mathrm{s}$ at the upper $8 \mathrm{~km}$ depth, the second one $3.65 \mathrm{~km} / \mathrm{s}$ at the depth from $8 \mathrm{~km}$ down to $18 \mathrm{~km}$, the third one a low-velocity zone at a thick layer, and the fourth one $3.85-3.90 \mathrm{~km} / \mathrm{s}$ at a thin layer. By referring to this layered model and a series of repeated tests, Liu et al. [41,42] constructed a slightly different structure model including four layers: from top to bottom, a 2.5-kilometer-thick layer with an $S$ wave velocity of $3.15 \mathrm{~km} / \mathrm{s}$, a 5-kilometer-thick layer with an $S$ wave velocity of $3.51 \mathrm{~km} / \mathrm{s}$, a 15-kilometer-thick layer with an $\mathrm{S}$ wave velocity of $3.63 \mathrm{~km} / \mathrm{s}$, and a 10-kilometer-thick layer with an S wave velocity of $3.69 \mathrm{~km} / \mathrm{s}$. With this layered model, Liu et al. [41,42] successfully derived the focal mechanism solutions of 98 aftershocks of the $2008 \mathrm{Mw} 6.3$ DCD earthquake, and relocated the aftershock sequences of the $2009 \mathrm{Mw}$ 6.3 DCD earthquake.

Based on these previous studies, a three-layered model is constructed in this study (Table 2). The thickness of the top layer is $8 \mathrm{~km}$ with an $\mathrm{S}$ wave velocity of $3.00 \mathrm{~km} / \mathrm{s}$, the middle one $15 \mathrm{~km}$ with an $S$ wave velocity of $3.65 \mathrm{~km} / \mathrm{s}$, and the bottom one infinite with an $S$ wave velocity of $3.50 \mathrm{~km} / \mathrm{s}$. The corresponding P wave velocities are calculated by assuming the Poisson's ratio equal to 0.25 [43], and the related densities are determined by using the empirical relationship between $P$ wave velocity and density [44]. It should be noted that the parameter of viscosity can be meaningful only in the modeling of the postseismic deformation time series.

Table 2. Layered model used in this study.

\begin{tabular}{cccccc}
\hline Layer No. & Thickness $\mathbf{( k m )}$ & $\mathbf{V p} \mathbf{( k m} / \mathbf{s})$ & $\mathbf{V s} \mathbf{( k m} / \mathbf{s})$ & Density $\mathbf{( k g / \mathbf { m } ^ { \mathbf { 3 } } )}$ & Viscosity $\mathbf{( P a} \cdot \mathbf{s})$ \\
\hline 1 & 8 & 5.19 & 3.00 & 2430.8 & N/A \\
2 & 15 & 6.31 & 3.65 & 2790.6 & N/A \\
3 & Infinite & 6.06 & 3.50 & 2707.6 & Variable \\
\hline
\end{tabular}

\section{Modeling Method}

In the modeling, the observed postseismic deformation time series are considered to relate to two mechanisms, postseismic afterslip and viscoelastic relaxation, where the viscoelastic relaxation 
is driven by both coseismic slip and the accumulated afterslip. This modeling method has been adopted to interpret the postseismic deformation observation following the earthquake, such as the 2011 Mw 9.0 Tohoku earthquake [33]. Meanwhile, Diao et al. [33] indicated that when investigating the postseismic process, it is necessary to consider the viscoelastic relaxation due to the accumulated afterslip. However, Diao et al. [33] assessed afterslip and viscoelastic relaxation separately, which will be improved to simultaneously estimate these two types of parameters.

The optimization problem for the modeling method can be expressed as:

$$
\left\|G s_{\text {post }}^{i}-\left(l^{i}-F^{i}\left(s_{c o}, s_{\text {post }}^{1}, \cdots, s_{\text {post }}^{i-1}, \eta\right)\right)\right\|^{2}+\beta^{2} H\left(s_{\text {post }}^{i}\right)=\min
$$

where $G$ is Green's function, $s_{\text {post }}^{i}$ is the postseismic afterslip at the $i$-th time epoch, $l^{i}$ is the postseismic deformation observation at the $i$-th time epoch, $F^{i}$ is the surface deformation produced by viscoelastic relaxation at the $i$-th time epoch, which is driven by the coseismic slip and the accumulated afterslip, $s_{c o}$ is the coseismic slip, $s_{\text {post }}^{1}, \cdots, s_{\text {post }}^{i-1}$ are the postseismic afterslips at the 1 -th, $\cdots, i-1$-th epoch times, $\eta$ is the regional viscosity, $\beta^{2}$ is the smoothing factor, and $H$ is the second-order Laplacian operator across the fault plane, which is used to avoid the unreasonable slip oscillation [39].

In Equation (1), coseismic slip, afterslip and viscosity are unknown parameters to be optimized. The Green's function related to afterslip is calculated with the EDGRN/EDCMP software (GFZ, Potsdam, Germany) [45], and the surface deformation produced by viscoelastic relaxation is calculated with the PSGRN/PSCMP software (GFZ, Potsdam, Germany) [46]. The viscosity is assumed to be constant during the observed time period. This assumption is accordant with the practices of modeling postseismic deformation of the 2008 M 6.4 and M 5.9 Nima-Gaize earthquakes, the $2008 \mathrm{Mw}$ 6.3 Dangxiong earthquake, and the $2011 \mathrm{Mw} 9.0$ Tohoku earthquake $[29,32,33]$, and is also proved to be reasonable by the following modeling experiments (Section 5).

The practical calculations mainly consist of four steps (Figure 3). In step 1, the postseismic viscoelastic relaxation deformation with different viscosities are simulated with the given coseismic slip distribution, the postseismic afterslip time series, the viscosity models, and so on. The input postseismic afterslip time series at the $i$-th time epoch are those estimated from the modeling with the same viscosity at the 1-th, $\ldots, i-1$-th time epochs. In step 2 , the differential postseismic deformation is calculated by subtracting the postseismic viscoelastic relaxation deformation in step 1 from the observed postseismic deformation. In step 3, with the differential postseismic deformation in step 2, the postseismic afterslip distribution is estimated using the steepest descent method [47], which has been proved as an effective technique to estimate the coseismic slip and postseismic afterslip [33,48]. In step 4, the trade-off curve between the viscosity and RMS misfit error for the combined observations at all-time epochs is plotted to choose the preferred viscosity, and then the optimal postseismic afterslip time series are determined as those derived with the preferred viscosity.

The advantage of this method is that the afterslip and the viscosity can be estimated simultaneously, compared to most of the existing studies [16,28-32]. This method is also slightly different from that in Diao et al. [33], in which these two types of unknown parameters are estimated separately, first the afterslip distribution and then the viscosity. The separate estimation in Diao et al. [33] might ignore the effect of viscoelastic relaxation on the afterslip distribution, because the input postseismic afterslip time series are directly estimated from modeling postseismic deformation with afterslip only.

During the calculation, the layered model (Table 2) is used to calculate all the postseismic deformation time series of the 2009 Mw 6.3 DCD earthquake. For the viscoelastic relaxation, the part beneath the seismogenic layer is globally considered as a viscoelastic half-space of a Maxwell-type body, and the viscosities are varied from $1 \times 10^{17} \mathrm{~Pa} \cdot \mathrm{s}$ to $1 \times 10^{22} \mathrm{~Pa} \cdot \mathrm{s}$ with an index increased by one each time to simulate the viscoelastic relaxation deformation. For the afterslip, the fault geometry is fixed as that derived by Liu et al. [3], and the fault plane is discretized into patches with a size of $1-\mathrm{km}$ length by $1-\mathrm{km}$ width to estimate the afterslip distribution. After modeling for the eight time 
epochs with all possible viscosities and plotting the trade-off curve between the viscosity and RMS misfit error, the preferred viscosity is chosen when the RMS misfit begins to stabilize. It should be noted that in order to better display the trade-off curve, the RMS misfit is plotted against the log value of the viscosity instead of the viscosity.

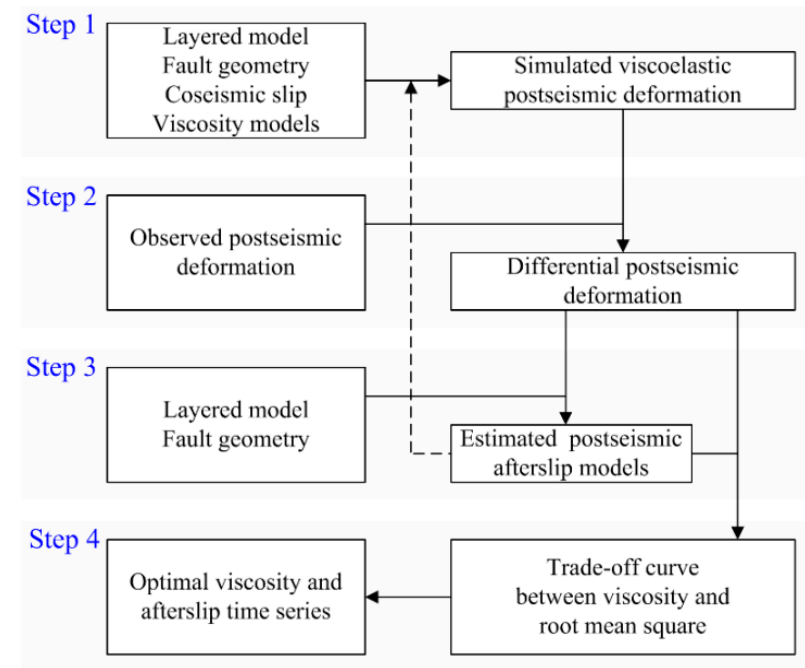

Figure 3. Flowchart of modeling postseismic deformation time series with a combination model of afterslip and viscoelastic relaxation. Both coseismic slip and the accumulated afterslip models occurring before the current time epoch are used to drive the viscoelastic relaxation.

\section{Coseismic Slip in the Layered Model}

When modeling the postseismic deformation time series with mechanisms related to the viscoelastic relaxation, coseismic slip is provided as the driving force source and then be thought as one key input parameter [28-31]. Therefore, a coseismic slip model that matches the postseismic process should be acquired. To achieve this, the dislocation Green's function should be calculated with the layered model instead of the elastic half-space [32], and the adopted observation dataset should be obtained in the shortest possible time after the earthquake.

Figure 4a shows the coseismic surface displacements for the 2009 Mw 6.3 DCD earthquake derived from two Envisat ASAR descending Track 319 images, which were observed on 14 January 2009 and 16 September 2009, respectively. The interferometric processing was done by using the ROI_PAC software (Caltech/JPL, Pasadena, CA, USA) [49], and the detailed data processing procedures can be found in Liu et al. [23]. The estimation method of coseismic slip distribution is close to that of modeling postseismic deformation with afterslip, with the difference that the postseismic deformation observation is replaced with the coseismic deformation.

Figure 5a,b show the derived coseismic slip distribution and uncertainties in the layered model. The uncertainties refer to the standard deviations in slip estimated from the Monte Carlo calculations with 100 perturbed datasets [3,50]. The fault rupturing model is characterized by three slip asperities, which are located at three fault segments, separately. The maximum slip is about $2.41 \mathrm{~m}$, which is located at the central segment. The slips of three fault segments are mainly located at a depth from $2.5 \mathrm{~km}$ to $8.2 \mathrm{~km}$, and are dominated by thrust motion. The estimated geodetic moment is $3.75 \times 10^{18} \mathrm{~N} \cdot \mathrm{m}$, equaling to a magnitude of Mw 6.35. The slip uncertainties range from $0 \mathrm{~m}$ to $0.12 \mathrm{~m}$, and most of them are less than $0.08 \mathrm{~m}$. For the main slipping fault patches, the uncertainties are obviously less than the corresponding slips, indicating that the slip model in Figure 5a is reliable. 


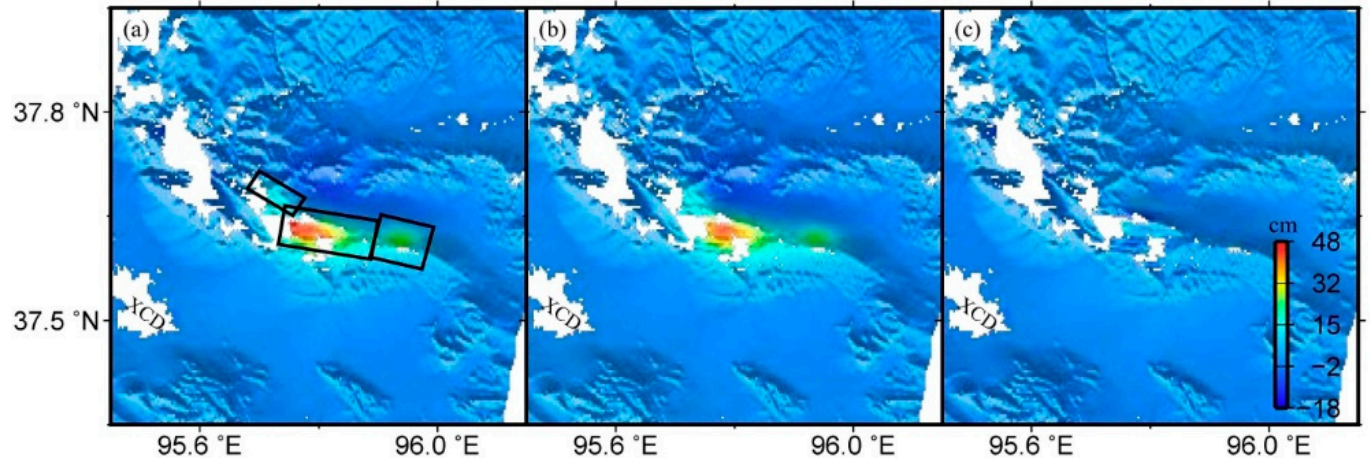

Figure 4. (a) Observed coseismic displacements for the 2009 Mw 6.3 DCD earthquake from two Envisat ASAR descending Track 319 images; (b) modeled displacements from the coseismic slip distribution in the layered model; and (c) residual displacements. Three rectangles in subfigure (a) indicate the surface projections of the fault geometry model. XCD is the abbreviated form of Xiaochaidan. Positive and negative values indicate motions toward and away from the satellite in the LOS direction, respectively.

(a)

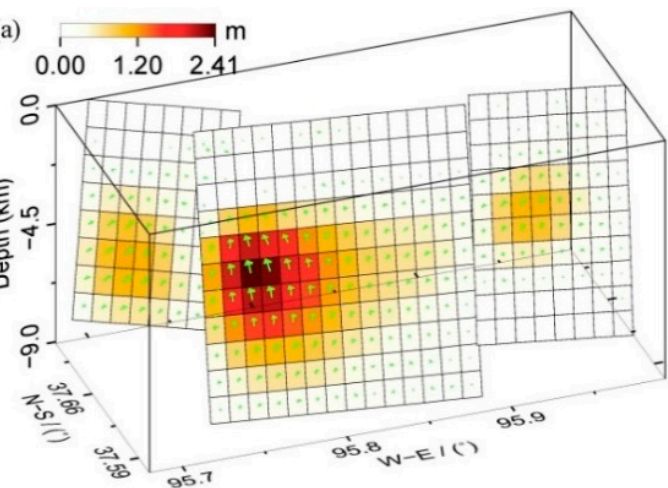

(b)

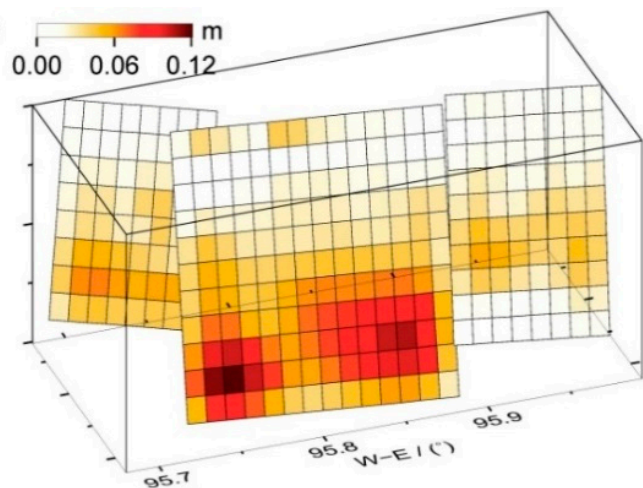

Figure 5. (a) Coseismic slip distribution of the 2009 DCD earthquake in the layered model; and (b) slip uncertainties estimated from the Monte Carlo calculation with 100 perturbed datasets. Green arrows in (a) indicate the slip direction on the corresponding fault patch.

The slip pattern in Figure 5a is generally consistent with that from the homogeneous half-space model [3]. Both models are dominated by thrust motion, have three slip asperities, and show no distinct slip for the upper three rows of fault patches. The maximum slips for the layered and homogeneous models are $2.41 \mathrm{~m}$ and $2.44 \mathrm{~m}$, and are both located at a depth between $4.1 \mathrm{~km}$ and $4.9 \mathrm{~km}$. Although the pattern and magnitude of these two slip models are very close, we still argue that the model derived from the layered model is a more realistic slip distribution, and adopt it as the driving force source when modeling the observed postseismic deformation time series.

Figure $4 b, c$ show the modeled and residual displacements from the coseismic slip distribution in the layered model. The observed and modeled displacements have a similar deformation pattern, with a decreasing trend from the main deformation zone to both eastern and western sides. The residual displacement shows no distinct deformation zone. These facts indicate that the slip model in Figure 5a can better interpret the observed coseismic surface deformation.

\section{Time-Dependent Afterslip and Viscosity}

\subsection{Time-Dependent Afterslip}

Using the modeling method (Section 3) and the observed postseismic deformation time series (Figure 2), the preferred time-dependent afterslip distribution and the viscosity can be estimated 
simultaneously. Figure 6 shows the temporal and spatial distribution of postseismic afterslip at the eight time epochs of InSAR observations, ranging from 19 days to 334 days after the main shock.

The temporal and spatial features of the postseismic afterslip in Figure 6 are analyzed as follows. On the whole, the afterslip shows continuity and its magnitude increases with time. By 21 October 2009, 54 days after the main shock, the afterslip mainly occurs on the central and eastern segments, and two separate slip zones exist on the central segment. By 30 December 2009, 124 days after the main shock, for the western segments, afterslip begins to occur on the deep patches; for the central segment, afterslip has a trend of extending to the upper zone, the two separate slip zones are almost connected together, and some afterslip begins to occur on the upper-right zone; for the eastern segment, afterslip also has a trend of extending to the upper zone. From 10 March 2010 to 19 May 2010, afterslip for each segment increases with time, and the upper-right slip zone gradually merges into the main bottom-left slip zone for the central segment. From that time until 28 July 2010, 334 days after the main shock, the slip pattern across all fault segments is stable, and its magnitude still increases with time.

The postseismic afterslip distribution 334 days after the main shock (Figure 6h) is then analyzed. It has a complex pattern, with a maximum of $0.302 \mathrm{~m}$ slip located at the central segment. For the western segment, the afterslip is dominated by thrust motion with a slight left-lateral strike-slip component; For the central segment, the afterslip is dominated by thrust motion with some right-lateral strike-slip component, except that the main deep slipping zone has a slight left-lateral strike-slip component; For the eastern segment, the afterslip is dominated by thrust motion with some right-lateral strike-slip component. The moment released by the afterslip is $0.91 \times 10^{18} \mathrm{~N} \cdot \mathrm{m}$, which is about $24.3 \%$ of the main shock and equals to a magnitude of Mw 5.94. This ratio is consistent with previous findings [28,32,51].

The afterslip in Figure 6 is then compared with that in Feng [22]. The significant afterslip zone at a depth of about 3-9 $\mathrm{km}$ can be both resolved by the two results, although there exist some differences. The afterslip in this study indicates an upper-right slip zone on the central segment, which was not detected by Feng [22]. However, Feng [22] indicated a slip zone at depths larger than $10 \mathrm{~km}$, which was not found in this study. The maximum afterslip detected by this study is $0.302 \mathrm{~m}$, which differs from that from Feng [22] by about $0.5 \mathrm{~m}$. The released moment is $0.91 \times 10^{18} \mathrm{~N} \cdot \mathrm{m}$, which is about one times less than that from Feng [22]. The reason for these differences may be that the two studies have adopted different datasets and inversion methods to do the modeling of postseismic deformation observations.

The uncertainties for the afterslip models on each date are estimated from the Monte Carlo calculations with 100 perturbed datasets, respectively (Figure 7) [3,50]. The spatial features of afterslip uncertainties are also complex, with larger values mostly located at the deeper zone. This is consistent with that in Bie et al. [32], which investigated the errors of the postseismic afterslip time series of the $2008 \mathrm{Mw}$ 6.3 Dangxiong earthquake using the same method. The uncertainty time series for each time epochs are obviously less than the corresponding afterslip time series, and the maximum uncertainty of $0.072 \mathrm{~m}$ is about three times less than that of the afterslip, indicating that the afterslip distribution time series are reliable in both temporal and spatial features. It is noted that the afterslip time series uncertainties do not show a trend of increasing with time.

The resolution test demonstrates that the input slip model, which has a slip pattern similar to the main slip (larger than $40 \%$ of its maximum afterslip) zone in Figure $6 \mathrm{~h}$, can be generally well resolved (Figure 8), indicating the afterslip in Figure 6 are spatially reliable. The slip patches in the fault plane at shallower depth are recovered better than those at deeper depth. The reason for this may be the lower spatial resolution in the fault plane at deeper depth for geodetic inversions, as has been demonstrated by other studies [32,50]. 


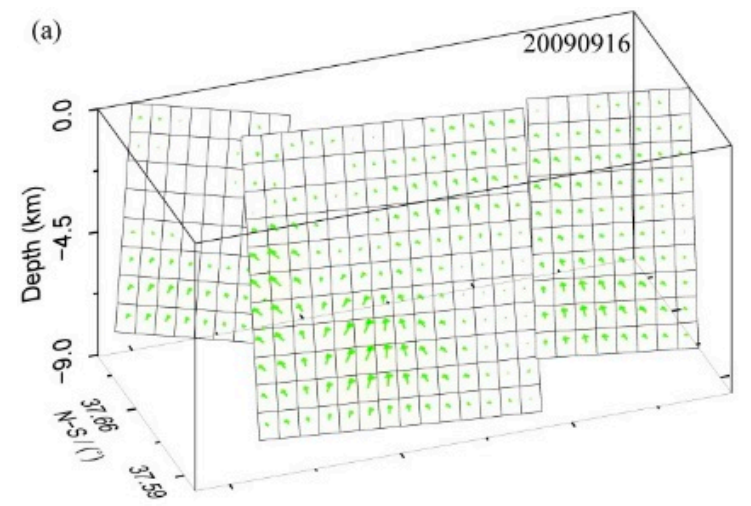

(b)
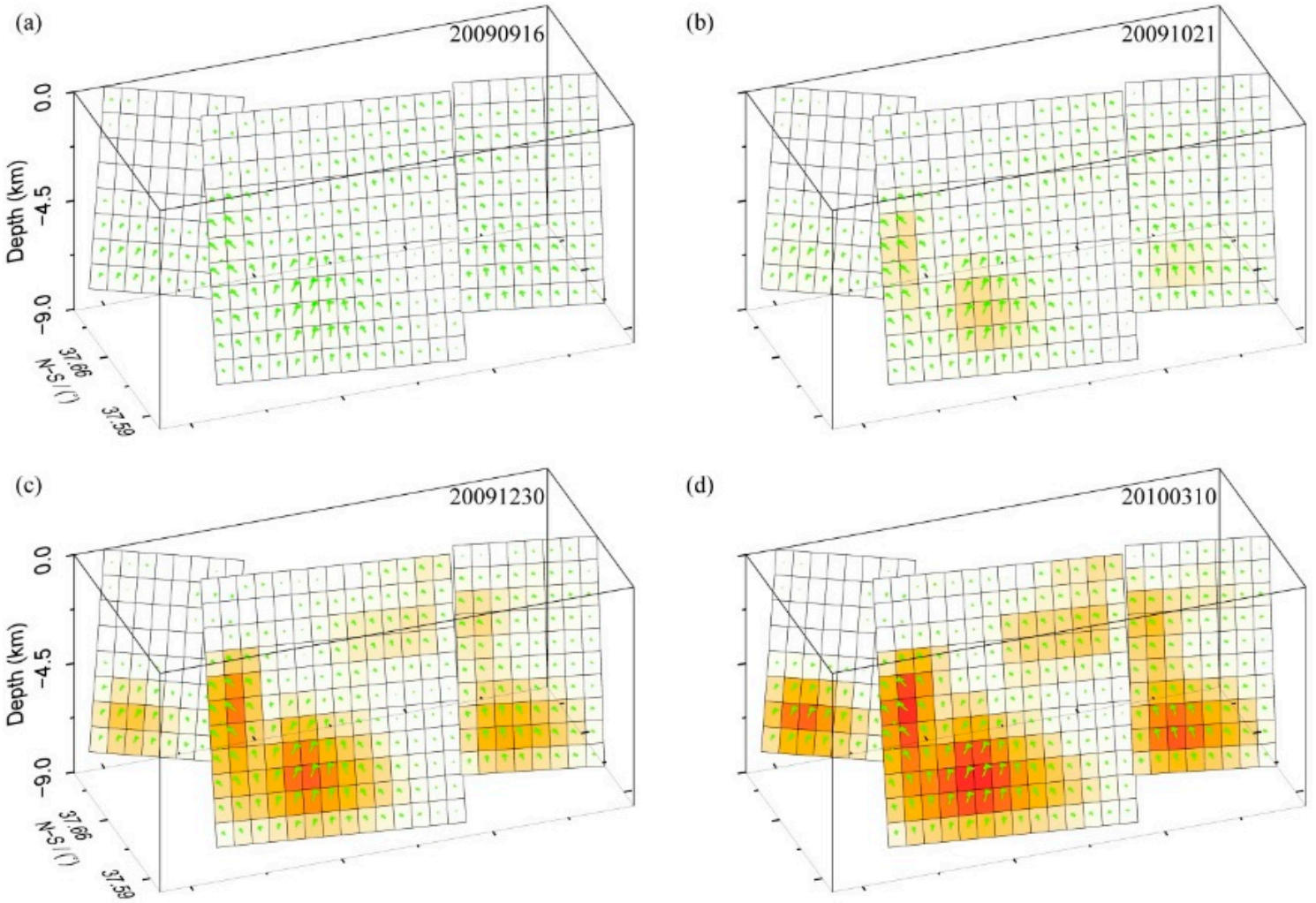

(d)
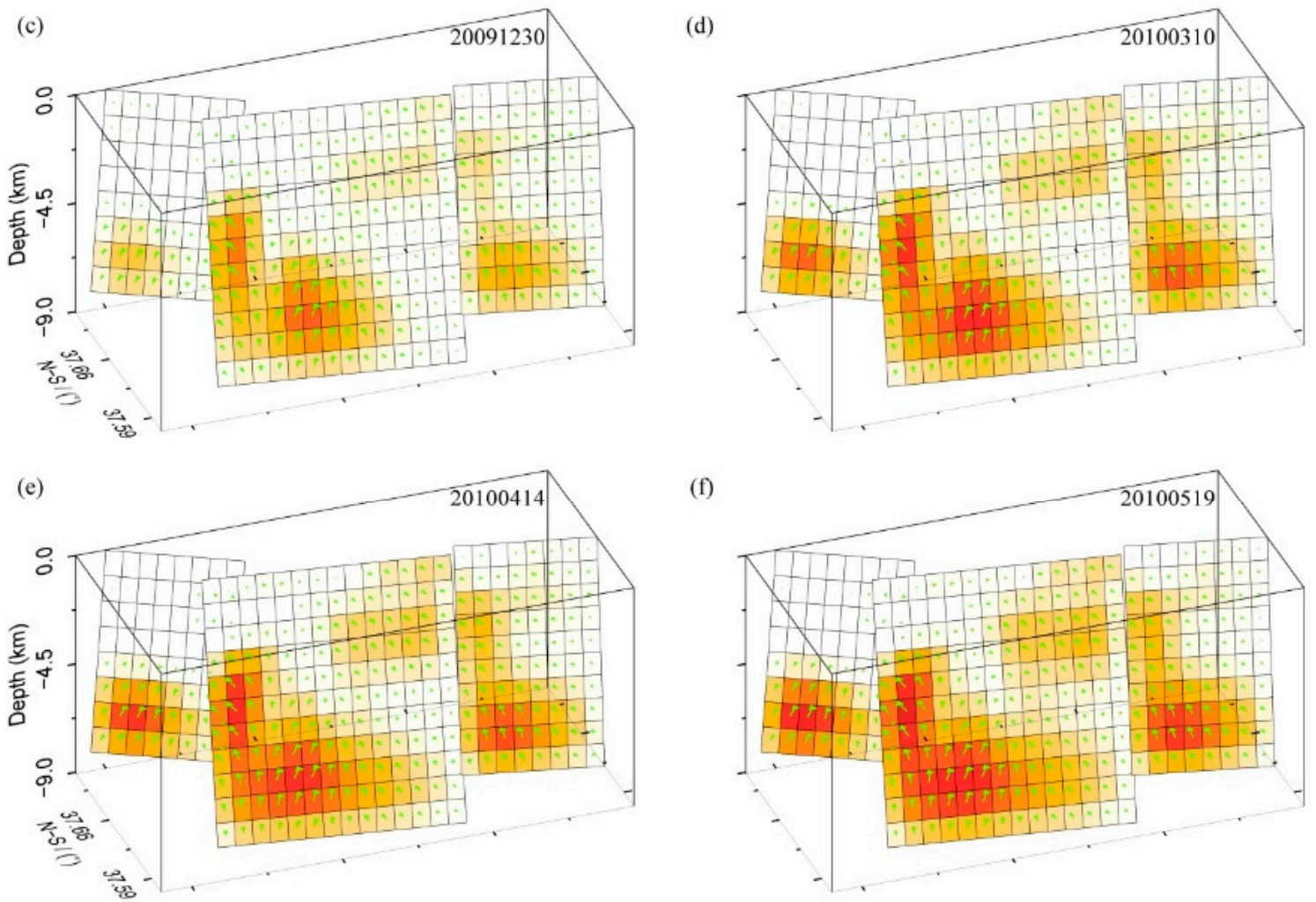

(f)
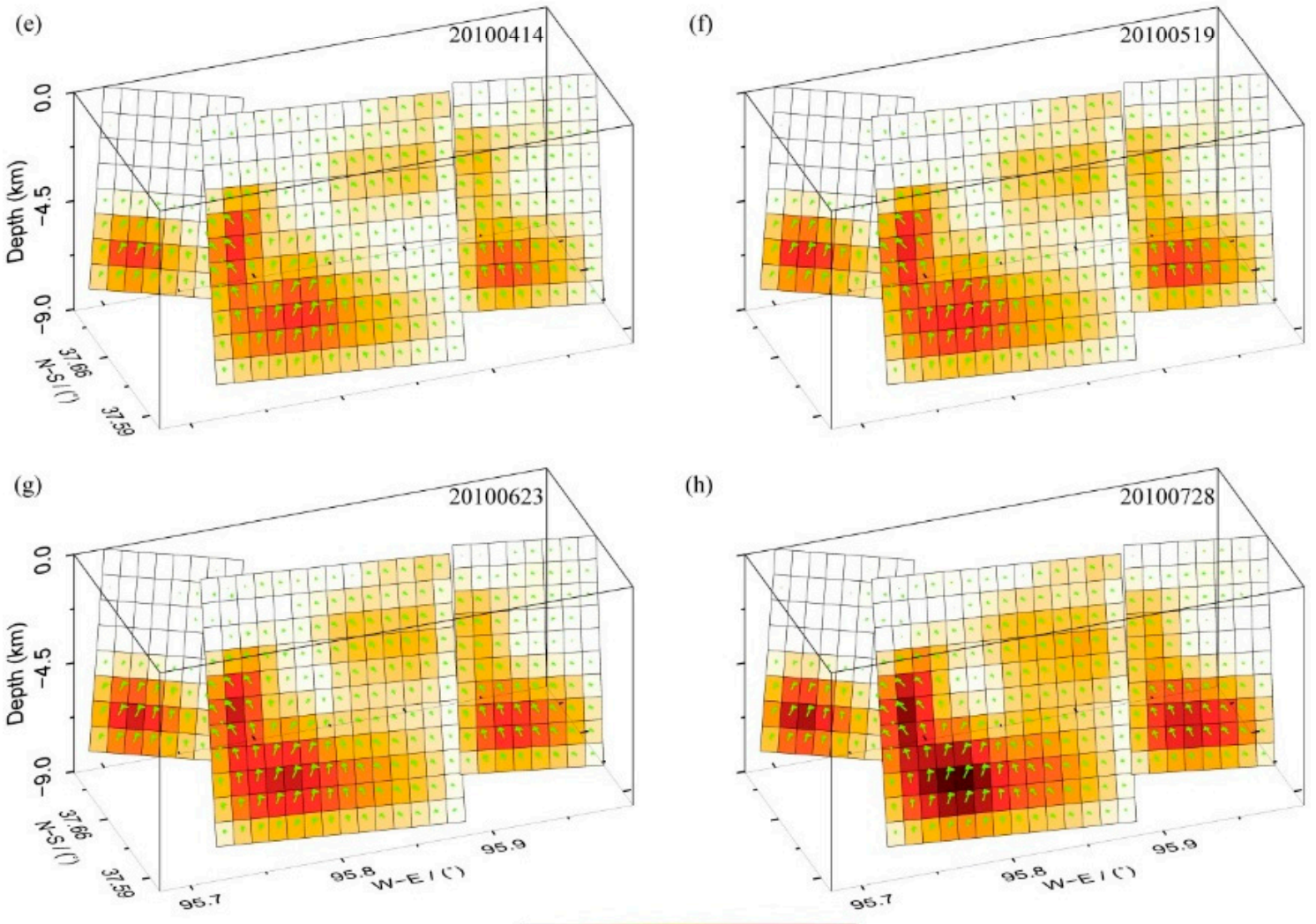

(h)

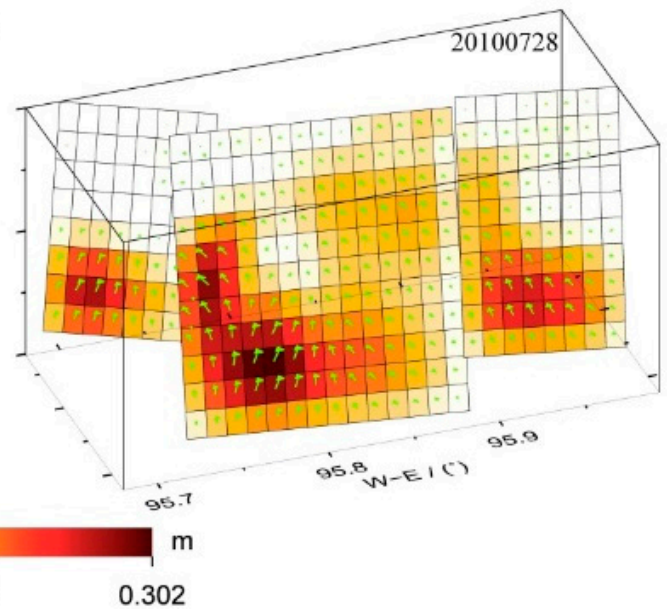

Figure 6. (a-h) Temporal and spatial distribution of postseismic afterslip, corresponding successively to the eight time epochs of InSAR observations. The characters labeled in all subfigures are the corresponding observation dates. Green arrows in all subfigures indicate the slip direction on the corresponding fault patch. 


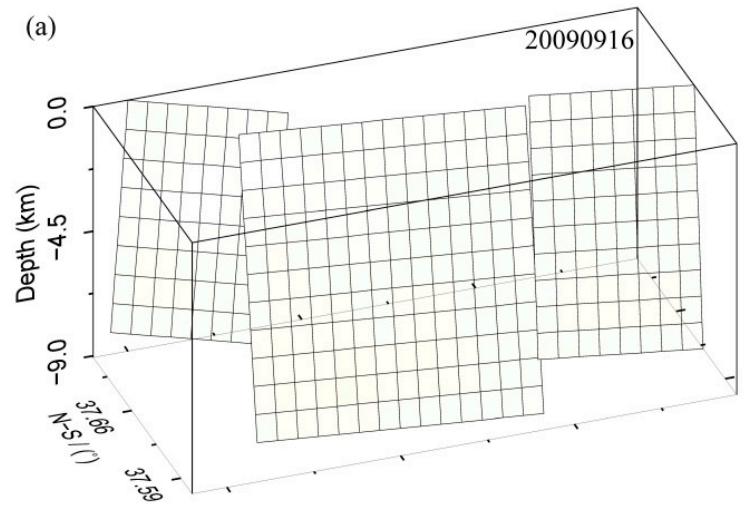

(b)
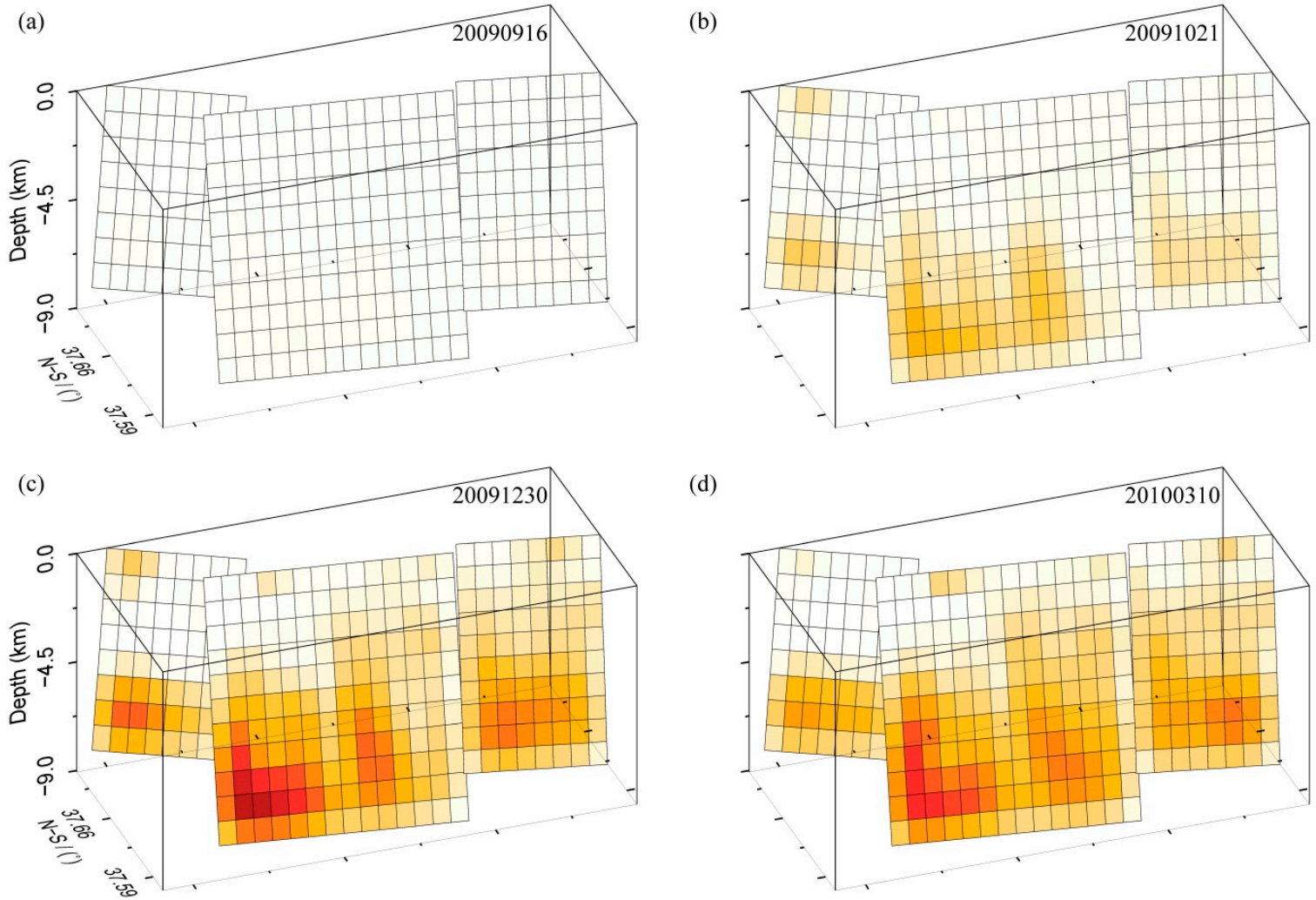

(d)
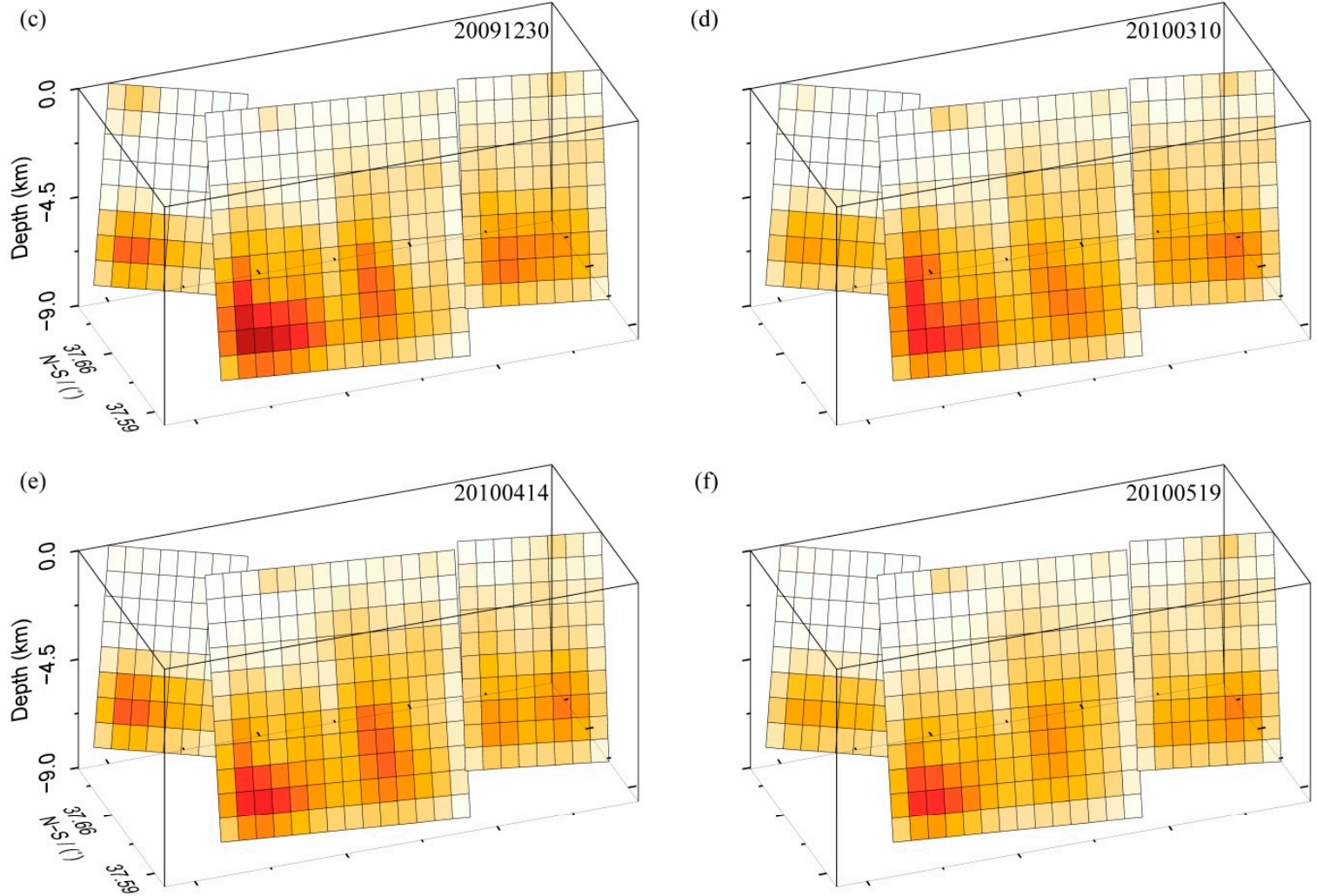

(f)
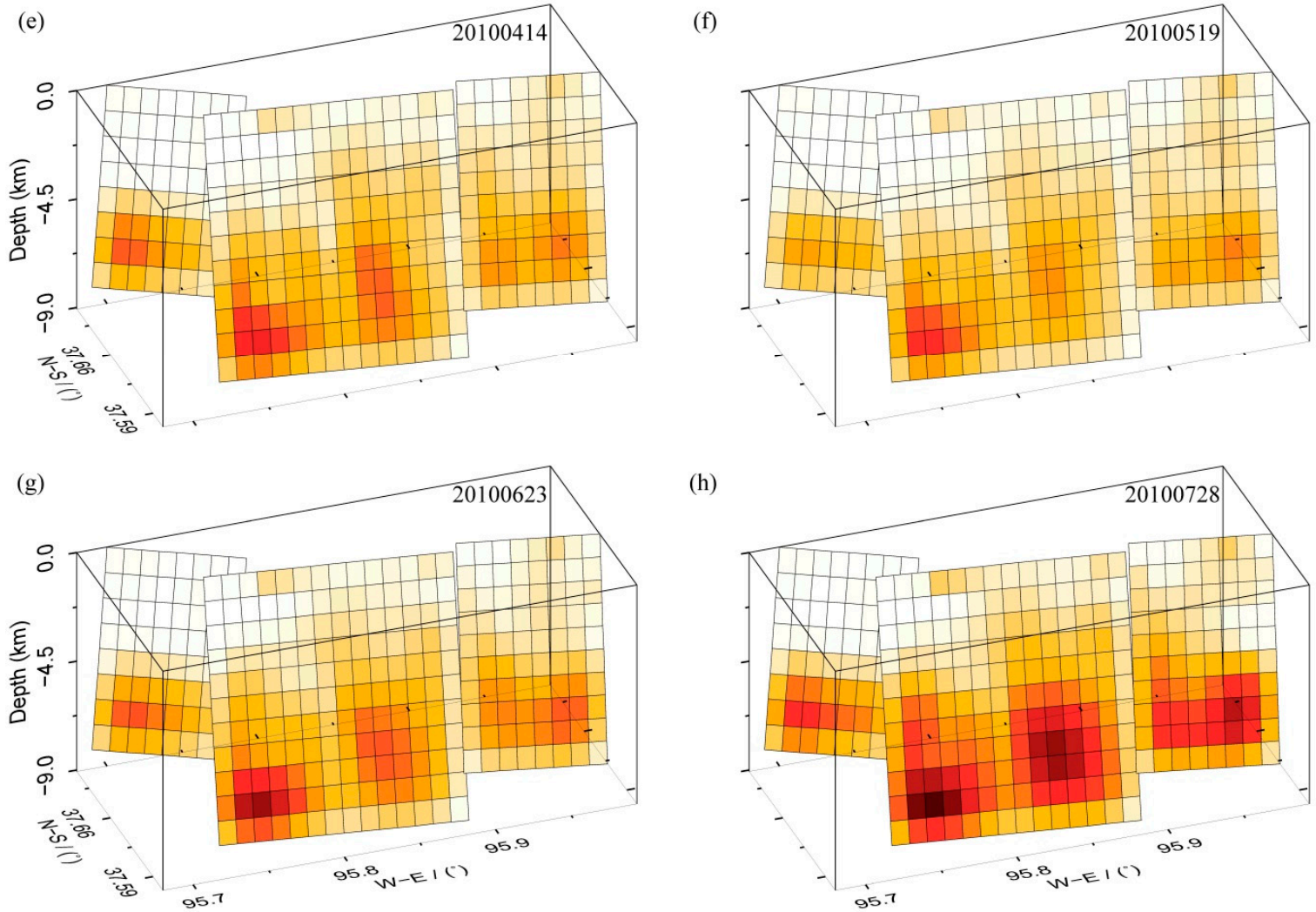

(h)

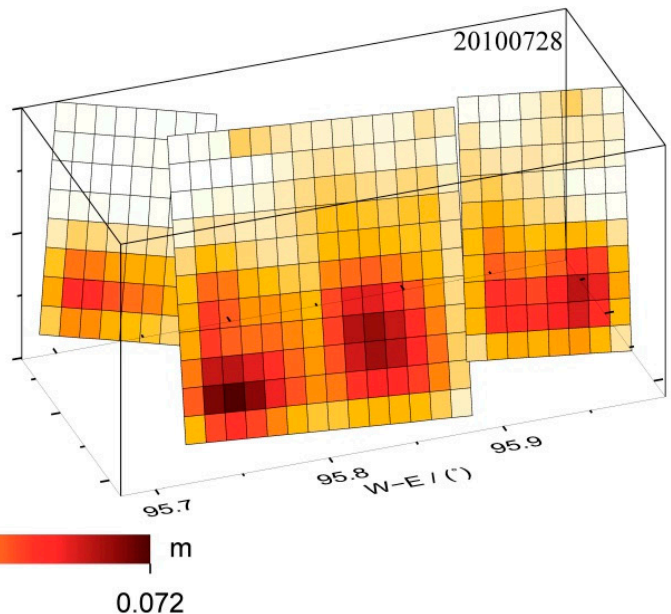

Figure 7. (a-h) Corresponding uncertainties for the afterslip models in Figure 6. These uncertainties for each date are estimated from the Monte Carlo calculation with 100 perturbed datasets, respectively. 

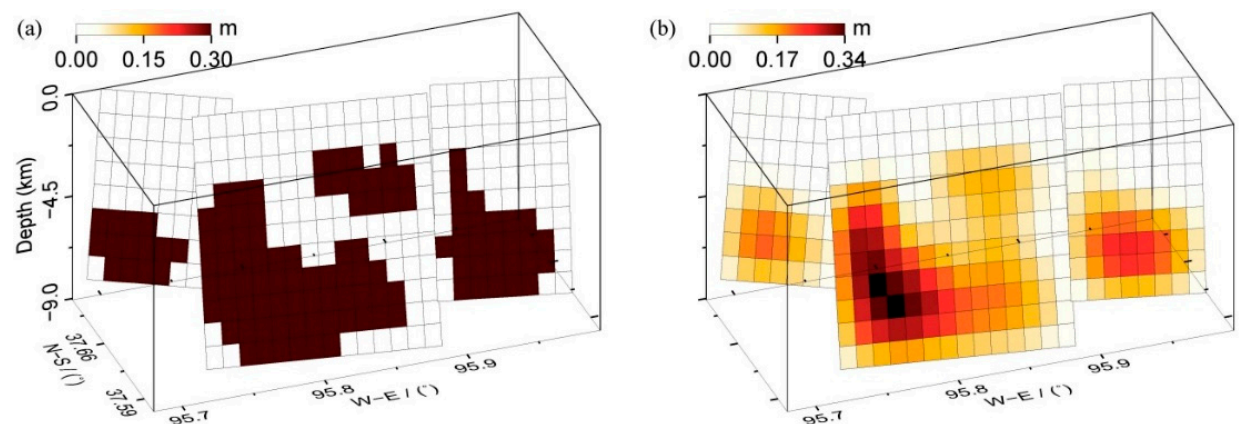

Figure 8. Resolution test. (a) Input slip model; and (b) recovered slip model. The input model in (a) has a slip pattern similar to the main slip (larger than $40 \%$ of its maximum afterslip) zone in Figure $6 \mathrm{~h}$.

\subsection{Viscosity}

Figure 9 shows the relationship curve between the log viscosity and the RMS misfit for the combined observations at the eight time epochs. It is clear that the RMS misfit decreases rapidly from $0.72 \mathrm{~cm}$ to $0.40 \mathrm{~cm}$ and then to $0.37 \mathrm{~cm}$ when the viscosity increases from $1 \times 10^{17} \mathrm{~Pa} \cdot \mathrm{s}$ to $1 \times 10^{18} \mathrm{~Pa} \cdot \mathrm{s}$ and then to $1 \times 10^{19} \mathrm{~Pa} \cdot \mathrm{s}$, and that the RMS misfit almost converges to a constant $(0.37 \mathrm{~cm})$ after the viscosity increasing to $1 \times 10^{19} \mathrm{~Pa} \cdot \mathrm{s}$. This RMS misfit is slightly larger than the average standard deviation $(0.31 \mathrm{~cm})$ of the eight postseismic deformation time series (Table 1$)$.

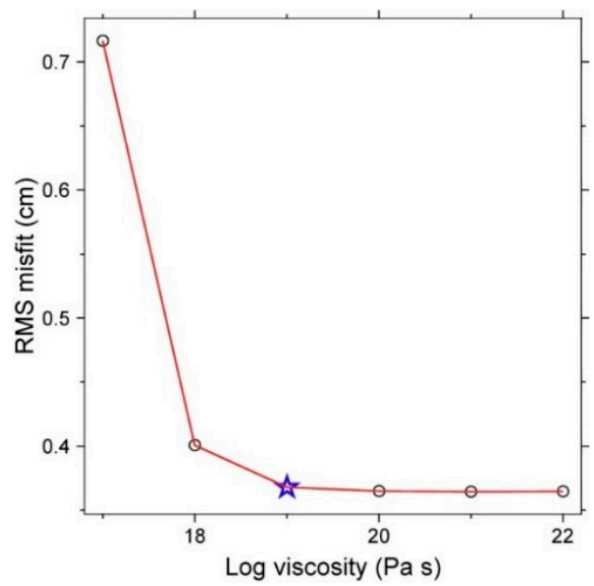

Figure 9. Relationship curve between the log viscosity and the RMS misfit for the combined observations at the eight time epochs. The blue hollow star denotes the preferred lower bound of the viscosity, $1 \times 10^{19} \mathrm{~Pa} \cdot \mathrm{s}$. Beyond this value the RMS misfit nearly no longer changes with viscosity.

The changing characteristic between RMS misfit and viscosity in Figure 9 is similar to those obtained by Ryder et al. [29] and Bie et al. [32], which modeled the postseismic InSAR deformation time series of the 2008 M 6.4 and M 5.9 Nima-Gaize earthquakes and the 2008 Mw 6.3 Dangxiong earthquake with a combined model of afterslip and viscoelastic relaxation in a Maxwell half-space. In Ryder et al. [29], the viscosity less than which the RMS misfit residual will increase rapidly is viewed as the lower bound on the Maxwell viscosity. Therefore, for this study the lower bound on the Maxwell viscosity is $1 \times 10^{19} \mathrm{~Pa} \cdot \mathrm{s}$.

Figure 10 shows the relationship curves between the log viscosity and the RMS misfit for the eight time epochs of postseismic deformation observations, separately. It is clear that for all of the time epochs, beyond the preferred lower bound of the viscosity $\left(1 \times 10^{19} \mathrm{~Pa} \cdot \mathrm{s}\right)$ in Figure 9 , the RMS misfits almost no longer change with viscosity. This fact potentially indicates that the viscosity does not change significantly during the first 334 days after the main shock. This is inconsistent with the 
result from Ryder et al. [28], which modeled the postseismic displacement time series following the 1997 Mw 7.6 Manyi earthquake, and suggested that the viscosity may change with time during the first about three years. The possible reason is that the observing time period in this study is about two times shorter than that in Ryder et al. [28]. If observations with longer periods of time are available, whether the viscosity beneath the 2009 Mw 6.3 DCD earthquake zone changes with time, may be confirmed.
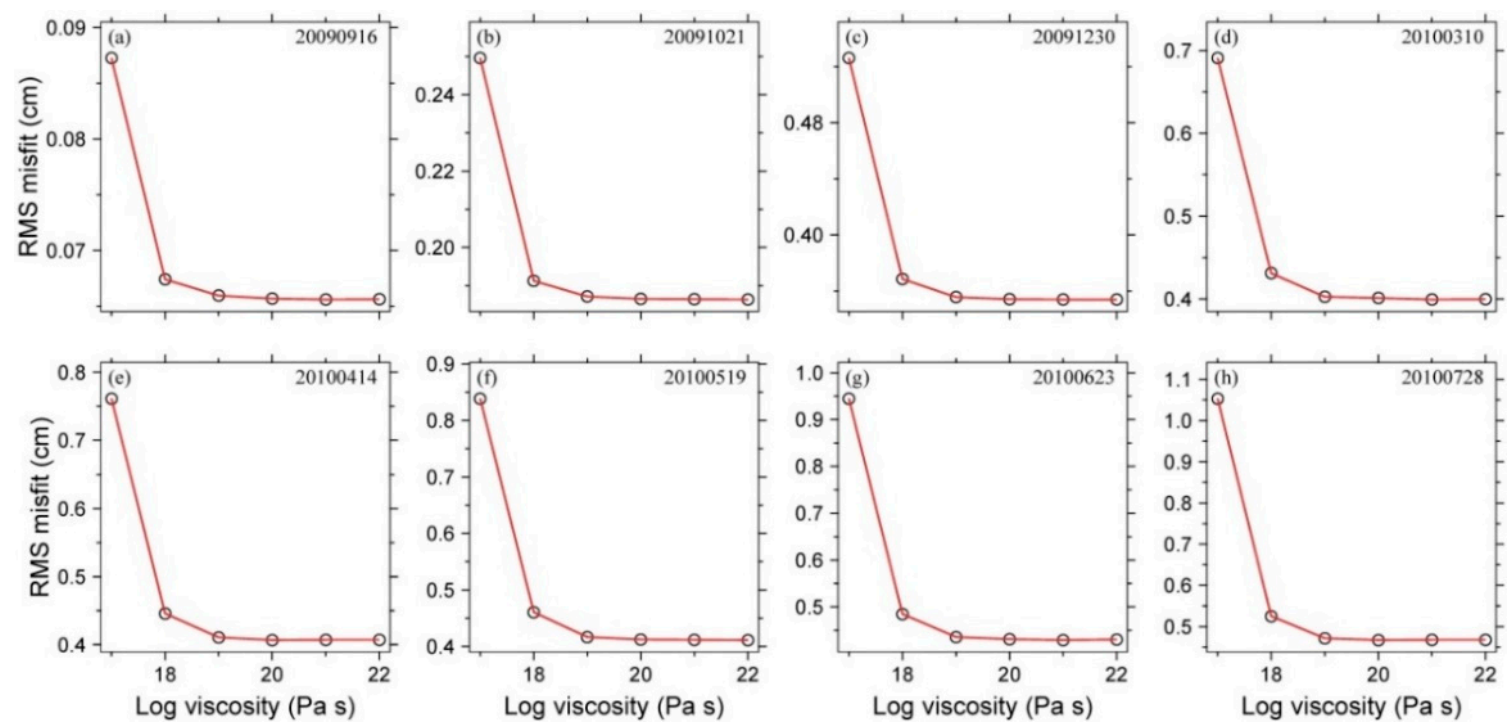

Figure 10. (a-h) Relationship curves between the log viscosity and the RMS misfit for the eight time epochs of postseismic deformation observations. For all of the time epochs, beyond the preferred lower bound of the viscosity in Figure 9, the RMS misfits almost no longer change with viscosity.

The RMS misfits for the eight postseismic deformation observations are $0.07 \mathrm{~cm}, 0.19 \mathrm{~cm}, 0.36 \mathrm{~cm}$, $0.40 \mathrm{~cm}, 0.41 \mathrm{~cm}, 0.42 \mathrm{~cm}, 0.44 \mathrm{~cm}$, and $0.47 \mathrm{~cm}$, respectively. These values are in close agreement with the corresponding standard deviations of the observed deformation (Table 1). Figure 2 shows the modeled and residual displacements time series derived from the preferred combination model of afterslip (Figure 6) and viscoelastic relaxation (a viscosity of $1 \times 10^{19} \mathrm{~Pa} \cdot \mathrm{s}$ ). It is clear that the combination model can well explain the observed postseismic deformation time series. For all eight time epochs, the surface uplift along LOS direction can be clearly seen across the hanging wall and has an increasing trend with time, and no significant deformation can be found across the footwall. In addition, the predicted deformation time series across the hanging wall display the spatial features of decreasing from the central to both sides. These temporal and spatial features are consistent with those in the observed deformation time series.

\section{Discussion}

\subsection{Comparison of Inversion Results from Different Methods}

To investigate the effect of neglecting viscoelastic relaxation due to the accumulated afterslip on the estimations of the postseismic moment release and the viscosity, the observed postseismic deformation time series were also modeled with afterslip and viscoelastic relaxation driven by coseismic slip only, named as Method 2 in Table 3. Here, the method of modeling with afterslip and viscoelastic relaxation due to both coseismic slip and accumulated afterslip, which is adopted and analyzed above, is named as Method 1. During the modeling, all of the parameters are configured as those in Method 1, with the exception that the viscoelastic relaxation deformation is only driven by the coseismic slip, but not the accumulated postseismic afterslip. With this method, the RMS misfit for all eight observations is consistent with that from Method 1 at the sub-millimeter level. The temporal and spatial distributions of the derived postseismic afterslip are very similar to those derived from Method 1. By 28 July 2010 , 
334 days after the main shock, the maximum slip, also located at the central segment, is $0.298 \mathrm{~m}$, which is slightly smaller than that $(0.302 \mathrm{~m})$ from Method 1 ; the moment released by postseismic afterslip is $9.02 \times 10^{17} \mathrm{~N} \cdot \mathrm{m}$, which is equal to an Mw of 5.937, compared to a moment of $9.07 \times 10^{17} \mathrm{~N} \cdot \mathrm{m}$ and an Mw of 5.938 from Method 1. The preferred lower bound of the viscosity is $1 \times 10^{19} \mathrm{~Pa} \cdot \mathrm{s}$, which is consistent with that from Method 1. In addition, the RMS misfit almost becomes stable after the viscosity increasing to $1 \times 10^{19}$. These similarities of the results between Methods 1 and 2 may be mainly related to the magnitudes of the accumulated postseismic afterslip. If the afterslip of the $2009 \mathrm{Mw}$ 6.3 DCD earthquake can have a comparable magnitude to that (a maximum afterslip of $3.8 \mathrm{~m}$ 564 days after the main shock ) of the $2011 \mathrm{Mw} 9.0$ Tohoku earthquake, then the effect of visocoelastic relaxation driven by the accumulated afterslip can be significant [33].

Table 3. Statistics of inversion results from different methods.

\begin{tabular}{ccccc}
\hline Method & Maximum Slip $^{\mathbf{a}} \mathbf{( m )}$ & Moment $\left.^{\mathbf{a}} \mathbf{( 1 0}^{\mathbf{1 6}} \mathbf{N} \cdot \mathbf{m}\right)$ & $\mathbf{M w}^{\mathbf{a}}$ & Viscosity (Pa.s) \\
\hline 1 & 0.302 & 90.68 & 5.938 & $1 \times 10^{19}$ \\
2 & 0.298 & 90.22 & 5.937 & $1 \times 10^{19}$ \\
3 & 0.274 & 87.26 & 5.927 & $\mathrm{~N} / \mathrm{A}$ \\
\hline \multicolumn{4}{r}{}
\end{tabular}

To investigate the effect of neglecting the viscoelastic relaxation due to both coseismic slip and accumulated afterslip on the estimations of the moment released by postseismic afterslip, the observed postseismic deformation time series were also modeled with afterslip only, named as Method 3 in Table 3. During the modeling, all the parameters are configured as those in Method 1, with the exception that the viscoelastic relaxtion deformation due to the coseismic slip and the accumulated postseismic afterslip is ignored. With this method, the RMS misfit for all eight observations is consistent with those from Methods 1 and 2 at the sub-millimeter level. The temporal and spatial distributions of the derived postseismic afterslip resemble those from Method 1 (Figure 6), but some differences still exist. By 28 July 2010, 334 days after the main shock, the maximum slip, also located at the central segment, is $0.274 \mathrm{~m}$, which is $0.028 \mathrm{~m}$ smaller than that from Method 1; the moment released by postseismic afterslip is $8.73 \times 10^{17} \mathrm{~N} \cdot \mathrm{m}$ (Mw 5.927), which is $0.34 \times 10^{17} \mathrm{~N} \cdot \mathrm{m}$ smaller than that from Method 1. Likewise, Wen et al. [11] investigated the postseismic deformation of the $2001 \mathrm{Mw}$ 7.8 Kokoxili earthquake, and found that the maximum slip for the preferred combination model is $0.57 \mathrm{~m}$, close to that from the afterslip model. These similarities of the results between Methods 1 and 3 may be mainly related to the length of postseismic observation time period. If postseismic deformation observations of tens, or even hundreds, of years are available, then the differences of results between Methods 1 and 3 would be obviously identified. In which case, the differences of results between Methods 1 and 2 would also be recognized.

A comparison of inversion results among three methods indicates that the effect of coseismic slip on the afterslip estimations is larger than that of the accumulated afterslip. 334 days after the main shock, the maximum afterslip and moment release for Method 2 are only $0.004 \mathrm{~m}$ and $0.05 \times 10^{17} \mathrm{~N} \cdot \mathrm{m}$ less than those from Method 1, compared to $0.028 \mathrm{~m}$ and $0.34 \times 10^{17} \mathrm{~N} \cdot \mathrm{m}$ for Method 3 . This is to be expected because the maximum afterslip 334 days after the main shock is only about $12.5 \%$ of the maximum coseismic slip.

\subsection{Depth of Afterslip for the 2009 DCD Earthquake}

Previous postseismic afterslip studies showed that the afterslip can occur at a depth comparable to the coseismic slip, and/or at a shallower depth, and/or below the coseismic rupture $[11,52,53]$. The different depths may reveal the frictional heterogeneities in and around the coseismic rupturing zone $[33,51]$.

The analysis of postseismic deformation time series for the 2009 Mw 6.3 DCD earthquake indicates that the afterslip mainly occurs at a depth of about $0-9.1 \mathrm{~km}$, rather than being limited to the very 
shallow upper crust. In comparison with the depth (about 2.5-8.2 km) of coseismic slip derived with the layered model (Section 4), the afterslip may extend from the coseismic slip zone to the shallower and deeper depths, respectively. In addition, during the observed period, the significant afterslip on a more deeper down-dip extension (larger than $9.1 \mathrm{~km}$ ) of the coseismic slip can be ruled out, due to that the 2008 Mw 6.3 DCD earthquake mainly occurred at a depth of about 9.5-24.5 km [1,3]. This is consistent with the results of Pollitz et al. [54], which argued that the significant deep afterslip was not the dominant modes of postseismic deformation at the time scales of about one year.

Depths of afterslip for some earthquakes in the Tibet Plateau have been investigated [11,28,29,32]. For the 2008 M 6.4 and M 5.9 Nima-Gaize earthquakes and the 2008 Mw 6.3 Dangxiong earthquake, the estimated afterslips mainly occurred at the comparable depth and the up-dip extension depth of coseismic slip [29,32]. For the 1997 Mw 7.6 Manyi earthquake and the $2001 \mathrm{Mw} 7.8$ Kokoxili earthquake, the estimated afterslips mainly occurred at the comparable depth and the down-dip extension depth of the coseismic slip [11,28]. The depths of afterslip for these earthquakes in the Tibet Plateau are inconsistent with each other. The reason for this may be related to the different frictional properties of materials beneath each earthquake, or the different time scales of postseismic observations.

\subsection{Viscosity Structure Beneath the Qaidam Basin}

The viscosity structure beneath the Tibet Plateau has been investigated by modeling other types of observations [55-60]. When interpreting the role of the viscosity structure in shaping the present-day topography of the Tibet Plateau, the results suggested that the viscosities range from $10^{16}$ to $10^{20} \mathrm{~Pa} \cdot \mathrm{s}$ [55-57]. When interpreting the role of the viscosity structure in producing the surface GPS velocity field in the India-Asia collision zone and the Northern Tibet Plateau, the results indicated that the viscosities range from $10^{18}$ to $10^{20} \mathrm{~Pa} \cdot \mathrm{s}$ [58,59]. When explaining the horizontality of palaeolake shorelines in the central Tibet Plateau, the results suggested that the viscosity of the middle to lower crust is at least $10^{19}-10^{20} \mathrm{~Pa} \cdot \mathrm{s}$ [60]. These studies demonstrated that the viscosity structure beneath the Tibet Plateau may vary.

Postseismic deformation observations can provide another way of quantitating the regional viscosity structure with better accuracy [16]. In the Tibet Plateau, several studies have investigated the regional viscosity with postseismic deformation. Ryder et al. [28,29] analyzed the postseismic InSAR deformation of the 1997 Mw 7.6 Manyi earthquake and the 2008 M 6.4 and M 5.9 Nima-Gaize earthquakes, and inferred the effective viscosities of about 3-10 × 10 $18 \mathrm{~Pa} \cdot \mathrm{s}$ and $3 \times 10^{17} \mathrm{~Pa} \cdot \mathrm{s}$ beneath the earthquake zones, respectively. Zhang et al. [61] modeled the postseismic leveling observations of the 1973 Luhuo Mw 7.9 earthquake and inferred the viscosities between $10^{19} \mathrm{~Pa} \cdot \mathrm{s}$ and $10^{21} \mathrm{~Pa} \cdot \mathrm{s}$ beneath the earthquake zone. Ryder et al. [30] and Wen et al. [11] modeled the postseismic InSAR and/or GPS time series of the $2001 \mathrm{Mw} 7.8$ Kokoxili earthquake and obtained the steady-state viscosities between $1 \times 10^{19} \mathrm{~Pa} \cdot \mathrm{s}$ and $2 \times 10^{19} \mathrm{~Pa} \cdot \mathrm{s}$ below the earthquake zone. The differences between them might be related to the different time periods and observations used for modeling. With the postseismic GPS observations of the $2008 \mathrm{Mw} 7.9$ Wenchuan earthquake, Xu et al. [12] found that the viscosity beneath the earthquake zone is larger than $3 \times 10^{18} \mathrm{~Pa} \cdot \mathrm{s}$. By fitting the postseismic InSAR observations of the $2008 \mathrm{Mw}$ 6.3 Dangxiong earthquake, Bie et al. [32] argued a viscosity of $1 \times 10^{18} \mathrm{~Pa} \cdot \mathrm{s}$ below the earthquake zone.

The 2009 Mw 6.3 DCD earthquake is located at the northern side of the Qaidam Basin (Figure 1), and in this study the preferred lower bound of the viscosity beneath this event is $1 \times 10^{19} \mathrm{~Pa} \cdot \mathrm{s}$. This value is consistent with those derived from the postseismic deformation of the $2001 \mathrm{Mw} 7.8$ Kokoxili earthquake [11,30]. It is known that these two earthquakes are located on the northern and southern sides of the Qaidam Basin, respectively. The consistency between the viscosities derived from the postseismic deformation observations of the two earthquakes potentially proves their reliabilities.

The derived viscosity in this study differs one or two orders of magnitude from those estimated from the postseismic deformation of the 2008 M 6.4 and M 5.9 Nima-Gaize earthquakes, the 2008 Mw 7.9 Wenchuan earthquake, and the $2008 \mathrm{Mw} 6.3$ Dangxiong earthquake [12,29,32]. These events 
are located on the different parts of the Tibet Plateau, compared to the $2009 \mathrm{Mw} 6.3$ DCD event. This inconsistency may be related to their relative positions in the Tibet Plateau. In addition, from another side, this fact potentially validates that the viscosity structure beneath the Tibet Plateau may vary laterally.

\section{Conclusions}

On 28 August 2009, an Mw 6.3 DCD earthquake occurred at the northern side of the Qaidam Basin. We modified a method of modeling the postseismic deformation time series with the combination model of afterslip and viscoelastic relaxation, and then can simultaneously estimate the time-dependent afterslip distribution and the viscosity beneath the earthquake zone. To obtain a more rational driving force source of viscoelastic relaxation, we invert for a coseismic slip model in the layered model, which gives a slip pattern with a maximum slip of $2.41 \mathrm{~m}$ comparable to that in the elastic half-space model. With the postseismic deformation observations, we investigate the time-dependent afterslip of the 2009 Mw 6.3 DCD earthquake and the viscosity beneath the northern side of the Qaidam Basin.

The combination model of afterslip and viscoelastic relaxation can interpret the observed postseismic InSAR time series, with a total RMS misfit of $0.37 \mathrm{~cm}$ comparable to the average uncertainty of all of the observations. The preferred time-dependent afterslip shows continuity and increases with time, which is mainly located at a depth from the surface to about $9.1 \mathrm{~km}$ underground. The changing trend of the moment released by afterslip indicates that the postseismic afterslip is likely to continue 334 days after the main shock. By 28 July 2010, the moment released by the afterslip was $0.91 \times 10^{18} \mathrm{~N} \cdot \mathrm{m}$, about $24.3 \%$ of the main shock, and equaled a magnitude of Mw 5.94. The simultaneously estimated lower bound of the viscosity beneath the northern side of the Qaidam Basin is $1 \times 10^{19} \mathrm{~Pa} \cdot \mathrm{s}$, close to that beneath the southern side of the Qaidam Basin. This viscosity differs from those beneath other parts of the Tibet Plateau potentially indicates that the viscosity structure beneath the Tibet Plateau may vary laterally.

Acknowledgments: This research is supported by the National Natural Science Foundation of China (No. 41404007, 41431069, and 41274030), the State Key Development Program for Basic Research of China (No. 2013CB733304), the Special Project of Basic Work of Science and Technology (No. 2015FY210400), and the China Scholarship Council (No. 201506275015). Part of this work is also supported by the UK Natural Environmental Research Council (NERC) through the LICS and CEDRRiC projects (ref. NE/K010794/1 and NE/N012151/1, respectively), and the ESA-MOST DRAGON-3 projects (ref. 10607 and 10665). We are grateful to editors and three anonymous reviewers for helping us improve the manuscript.

Author Contributions: Yang Liu and Caijun Xu conceived and designed the experiments; Yang Liu, Zhenhong Li, Yangmao Wen, Jiajun Chen, and Zhicai Li performed and analyzed the experiments; all authors wrote the paper.

Conflicts of Interest: The authors declare no conflict of interest.

\section{Abbreviations}

The following abbreviations are used in this manuscript:

$\begin{array}{ll}\text { DCD } & \text { Dachaidan } \\ \text { NWW } & \text { northwestern-west } \\ \text { SEE } & \text { southeastern-east } \\ \text { GPS } & \text { Global Positioning System } \\ \text { InSAR } & \text { Interferometric Synthetic Aperture Radar } \\ \text { ASAR } & \text { Advanced Synthetic Aperture Radar } \\ \text { USGS } & \text { United States Geological Survey } \\ \text { XCD } & \text { Xiaochaidan } \\ \text { LOS } & \text { line-of-sight } \\ \text { RMS } & \text { root mean square }\end{array}$




\section{References}

1. Elliott, J.; Parsons, B.; Jackson, J.; Shan, X.; Sloan, R.; Walker, R. Depth segmentation of the seismogenic continental crust: The 2008 and 2009 Qaidam earthquakes. Geophys. Res. Lett. 2011, 38. [CrossRef]

2. Liu, W.; Wang, P.; Ma, Y.; Chen, Y. Relocation of Dachaidan Ms 6.4 earthquake sequence in Qinghai province in 2009 using the double difference location method. Plateau Earthq. Res. 2011, 23, 24-26.

3. Liu, Y.; Xu, C.; Wen, Y.; Fok, H.S. A new perspective on fault geometry and slip distribution of the 2009 Dachaidan Mw 6.3 earthquake from InSAR observations. Sensors 2015, 15, 16786-16803. [CrossRef] [PubMed]

4. USGS. Magnitude 6.2-Northern Qinghai, China. Available online: http://earthquake.usgs.gov/ earthquakes/eqinthenews/2009/us2009kwaf/ (accessed on 23 May 2016).

5. Deng, Q.; Zhang, P.; Ran, Y.; Yang, X.; Min, W.; Chu, Q. Basic characteristics of active tectonics of China. Sci. China Ser. D 2003, 46, 356-372.

6. Zhang, P.; Deng, Q.; Zhang, G.; Ma, J.; Gan, W.; Min, W.; Mao, F.; Wang, Q. Active tectonic blocks and strong earthquakes in the continent of China. Sci. China Ser. D 2003, 46, 13-24.

7. Reilinger, R. Evidence for postseismic viscoelastic relaxation following the $1959 \mathrm{M}=7.5$ Hebgen Lake, Montana, earthquake. J. Geophys. Res. 1986, 91, 9488-9494. [CrossRef]

8. Pollitz, F.F.; Peltzer, G.; Bürgmann, R. Mobility of continental mantle: Evidence from postseismic geodetic observations following the 1992 Landers earthquake. J. Geophys. Res. 2000, 105, 8035-8054. [CrossRef]

9. Pollitz, F.F.; Wicks, C.; Thatcher, W. Mantle flow beneath a continental strike-slip fault: Postseismic deformation after the 1999 Hector Mine earthquake. Science 2001, 293, 1814-1818. [CrossRef] [PubMed]

10. Tronin, A.A. Satellite remote sensing in seismology. Remote Sens. 2009, 2, 124-150. [CrossRef]

11. Wen, Y.; Li, Z.; Xu, C.; Ryder, I.; Bürgmann, R. Postseismic motion after the $2001 \mathrm{Mw} 7.8$ Kokoxili earthquake in Tibet observed by InSAR time series. J. Geophys. Res. 2012, 117. [CrossRef]

12. Xu, C.; Fan, Q.; Wang, Q.; Yang, S.; Jiang, G. Postseismic deformation after 2008 Wenchuan Earthquake. Surv. Rev. 2014, 46, 432-436. [CrossRef]

13. Spinler, J.C.; Bennett, R.A.; Walls, C.; Lawrence, S.; González García, J.J. Assessing long-term postseismic deformation following the M7.2 4 April 2010, El Mayor-Cucapah earthquake with implications for lithospheric rheology in the Salton Trough. J. Geophys. Res. 2015, 120, 3664-3679. [CrossRef]

14. $\mathrm{Xu}, \mathrm{B}$; $\mathrm{Xu}, \mathrm{C}$. Numerical simulation of influences of the earth medium's lateral heterogeneity on co-and post-seismic deformation. Geod. Geodyn. 2015, 6, 46-54. [CrossRef]

15. Hamling, I.J.; Hreinsdóttir, S. Reactivated afterslip induced by a large regional earthquake, Fiordland, New Zealand. Geophys. Res. Lett. 2016, 43, 2526-2533. [CrossRef]

16. Huang, M.-H.; Bürgmann, R.; Pollitz, F. Lithospheric rheology constrained from twenty-five years of postseismic deformation following the $1989 \mathrm{M} \mathrm{w}$ 6.9 Loma Prieta earthquake. Earth Planet. Sci. Lett. 2016, 435, 147-158. [CrossRef]

17. Wen, Y.; Xu, C.; Liu, Y.; Jiang, G. Deformation and source parameters of the $2015 \mathrm{Mw} 6.5$ earthquake in Pishan, western China, from Sentinel-1A and ALOS-2 data. Remote Sens. 2016, 8. [CrossRef]

18. $\mathrm{Xu}, \mathrm{C} . ; \mathrm{Xu}, \mathrm{B}$;; Wen, Y.; Liu, Y. Heterogeneous fault mechanisms of the 6 October $2008 \mathrm{Mw} 6.3$ Dangxiong (Tibet) earthquake using Interferometric Synthetic Aperture Radar observations. Remote Sens. 2016, 8. [CrossRef]

19. Evans, E.L.; Meade, B.J. Geodetic imaging of coseismic slip and postseismic afterslip: Sparsity promoting methods applied to the great Tohoku earthquake. Geophys. Res. Lett. 2012, 39. [CrossRef]

20. Gan, W.; Zhang, P.; Shen, Z.-K.; Niu, Z.; Wang, M.; Wan, Y.; Zhou, D.; Cheng, J. Present-day crustal motion within the Tibetan Plateau inferred from GPS measurements. J. Geophys. Res. 2007, 112. [CrossRef]

21. Liu, Y.; Xu, C.; Wen, Y.; He, P. The InSAR coseismic deformation observation and fault parameter inversion of the 2008 Dachaidan Mw 6.3 earthquake. Acta Geod. Cart. Sin. 2015, 44, 1202-1209.

22. Feng, W. Modelling Co- and Post-Seismic Displacements Revealed by InSAR, and their Implications for Fault Behaviour. Ph.D. Thesis, University of Glasgow, Glasgow, UK, 2015.

23. Liu, Y.; Xu, C.; Wen, Y.; Li, Z. Post-seismic deformation from the $2009 \mathrm{Mw} 6.3$ Dachaidan earthquake in the northern Qaidam Basin detected by small baseline subset InSAR technique. Sensors 2016, 16. [CrossRef] [PubMed]

24. Peltzer, G.; Saucier, F. Present-day kinematics of Asia derived from geologic fault rates. J. Geophys. Res. 1996, 101, 27943-27956. [CrossRef] 
25. Massonnet, D.; Feigl, K.; Rossi, M.; Adragna, F. Radar interferometric mapping of deformation in the year after the Landers earthquake. Nature 1994, 369, 227-230. [CrossRef]

26. Fialko, Y. Evidence of fluid-filled upper crust from observations of postseismic deformation due to the 1992 Mw 7. 3 Landers earthquake. J. Geophys. Res. 2004, 109. [CrossRef]

27. Johanson, I.A.; Fielding, E.J.; Rolandone, F.; Burgmann, R. Coseismic and postseismic slip of the 2004 Parkfield earthquake from space-geodetic data. Bull. Seismol. Soc. Am. 2006, 96, 269-282. [CrossRef]

28. Ryder, I.; Parsons, B.; Wright, T.J.; Funning, G.J. Post-seismic motion following the 1997 Manyi (Tibet) earthquake: InSAR observations and modelling. Geophys. J. Int. 2007, 169, 1009-1027. [CrossRef]

29. Ryder, I.; Bürgmann, R.; Sun, J. Tandem afterslip on connected fault planes following the 2008 Nima-Gaize (Tibet) earthquake. J. Geophys. Res. 2010, 115, B03404. [CrossRef]

30. Ryder, I.; Bürgmann, R.; Pollitz, F. Lower crustal relaxation beneath the Tibetan Plateau and Qaidam Basin following the 2001 Kokoxili earthquake. Geophys. J. Int. 2011, 187, 613-630. [CrossRef]

31. Biggs, J.; Burgmann, R.; Freymueller, J.T.; Lu, Z.; Parsons, B.; Ryder, I.; Schmalzle, G.; Wright, T. The postseismic response to the 2002 M 7.9 Denali Fault earthquake: Constraints from InSAR 2003-2005. Geophys. J. Int. 2009, 176, 353-367. [CrossRef]

32. Bie, L.; Ryder, I.; Nippress, S.E.J.; Bürgmann, R. Coseismic and post-seismic activity associated with the 2008 Mw 6.3 Damxung earthquake, Tibet, constrained by InSAR. Geophys. J. Int. 2014, 196, 788-803. [CrossRef]

33. Diao, F.; Xiong, X.; Wang, R.; Zheng, Y.; Walter, T.R.; Weng, H.; Li, J. Overlapping post-seismic deformation processes: Afterslip and viscoelastic relaxation following the $2011 \mathrm{Mw} 9.0$ Tohoku (Japan) earthquake. Geophys. J. Int. 2014, 196, 218-229. [CrossRef]

34. Brown, L.D.; Reilinger, R.E.; Holdahl, S.R.; Balazs, E.I. Postseismic crustal uplift near Anchorage, Alaska. J. Geophys. Res. 1977, 82, 3369-3378. [CrossRef]

35. Shen, Z.K.; Jackson, D.D.; Feng, Y.; Cline, M.; Kim, M.; Fang, P.; Bock, Y. Postseismic deformation following the Landers earthquake, California, 28 June 1992. Bull. Seismol. Soc. Am. 1994, 84, 780-791.

36. Savage, J.; Svarc, J. Postseismic deformation associated with the $1992 \mathrm{Mw}=7.3$ Landers earthquake, southern California. J. Geophys. Res. 1997, 102, 7565-7577. [CrossRef]

37. Hsu, Y.J.; Bechor, N.; Segall, P.; Yu, S.B.; Kuo, L.C.; Ma, K.F. Rapid afterslip following the 1999 Chi-Chi, Taiwan earthquake. Geophys. Res. Lett. 2002, 29, 1-4. [CrossRef]

38. Chen, G.; Xu, X.; Zhu, A.; Zhang, X.; Yuan, R.; Klinger, Y.; Nocquet, J.-M. Seismotectonics of the 2008 and 2009 Qaidam earthquakes and its implication for regional tectonics. Acta Geol. Sin. 2013, 87, 618-628.

39. Parsons, B.; Wright, T.; Rowe, P.; Andrews, J.; Jackson, J.; Walker, R.; Khatib, M.; Talebian, M.; Bergman, E.; Engdahl, E. The 1994 Sefidabeh (eastern Iran) earthquakes revisited: New evidence from satellite radar interferometry and carbonate dating about the growth of an active fold above a blind thrust fault. Geophys. J. Int. 2006, 164, 202-217. [CrossRef]

40. An, C.; Song, Z.; Chen, G.; Chen, L.; Zhuang, Z.; Fu, Z.; Lu, Z.; Hu, J. 3-D shear velocity structure in north-west China. Chin. J. Geophys. 1993, 36, 317-325.

41. Liu, W.; Zhang, X.; Hu, Y. Accurate location of Dachaidan Ms 6.3 earthquake sequence and earthquake tectonic using the double-difference earthquake location method. Plateau Earthq. Res. 2012, 24, 20-24.

42. Liu, W.; Zhang, X.; Shi, Y.; Wen, Y.; Zhao, Y. Using green function database and quick moment tensor inversion calculating the focal mechanism solution of aftershocks of Dachaidan Ms 6.4 earthquake in 2008 in Qinghai province. Northwest. Seismol. J. 2012, 34, 154-160.

43. Owens, T.J.; Zandt, G. Implications of crustal property variations for models of Tibetan plateau evolution. Nature 1997, 387, 37-43. [CrossRef]

44. Berteussen, K.A. Moho depth determinations based on spectral ratio analysis of NORSAR long-period P waves. Phys. Earth Planet. Inter. 1977, 31, 313-326. [CrossRef]

45. Wang, R.; Martin, F.L.; Roth, F. Computation of deformation induced by earthquakes in a multi-layered elastic crust-FORTRAN programs EDGRN/EDCMP. Comput. Geosci. 2003, 29, 195-207. [CrossRef]

46. Wang, R.; Lorenzo-Martin, F.; Roth, F. PSGRN/PSCMP-A new code for calculating co-and post-seismic deformation, geoid and gravity changes based on the viscoelastic-gravitational dislocation theory. Comput. Geosci. 2006, 32, 527-541. [CrossRef]

47. Wang, R.; Diao, F.; Hoechner, A. SDM-A geodetic inversion code incorporating with layered crust structure and curved fault geometry. In Proceedings of the EGU General Assembly, Vienna, Austria, 7-12 April 2013. 
48. Wen, Y.; Xu, C.; Liu, Y.; Jiang, G.; He, P. Coseismic slip in the 2010 Yushu earthquake (China), constrained by wide-swath and strip-map InSAR. Nat. Hazards Earth Syst. Sci. 2013, 13, 35-44. [CrossRef]

49. Rosen, P.A.; Hensley, S.; Peltzer, G.; Simons, M. Updated repeat orbit interferometry package released. Eos Trans. AGU 2004, 85. [CrossRef]

50. Wright, T.J.; Lu, Z.; Wicks, C. Source model for the Mw 6.7, 23 October 2002, Nenana Mountain earthquake (Alaska) from InSAR. Geophys. Res. Lett. 2003, 30. [CrossRef]

51. Lin, Y.-n.N.; Sladen, A.; Ortega-Culaciati, F.; Simons, M.; Avouac, J.-P.; Fielding, E.J.; Brooks, B.A.; Bevis, M.; Genrich, J.; Rietbrock, A. Coseismic and postseismic slip associated with the 2010 Maule Earthquake, Chile: Characterizing the Arauco Peninsula barrier effect. J. Geophys. Res. 2013, 118, 3142-3159. [CrossRef]

52. Marone, C.J.; Scholtz, C.; Bilham, R. On the mechanics of earthquake afterslip. J. Geophys. Res. 1991, 96, 8441-8452. [CrossRef]

53. Bürgmann, R.; Ergintav, S.; Segall, P.; Hearn, E.H.; McClusky, S.; Reilinger, R.E.; Woith, H.; Zschau, J. Time-dependent distributed afterslip on and deep below the Izmit earthquake rupture. Bull. Seismol. Soc. Am. 2002, 92, 126-137. [CrossRef]

54. Pollitz, F.F.; Bürgmann, R.; Thatcher, W. Illumination of rheological mantle heterogeneity by the M7.2 2010 El Mayor-Cucapah earthquake. Geochem. Geophys. Geosyst. 2012, 13. [CrossRef]

55. Clark, M.K.; Royden, L.H. Topographic ooze: Building the eastern margin of Tibet by lower crustal flow. Geology 2000, 28, 703-706. [CrossRef]

56. Cook, K.L.; Royden, L.H. The role of crustal strength variations in shaping orogenic plateaus, with application to Tibet. J. Geophys. Res. 2008, 113. [CrossRef]

57. Bendick, R.; McKenzie, D.; Etienne, J. Topography associated with crustal flow in continental collisions, with application to Tibet. Geophys. J. Int. 2008, 175, 375-385. [CrossRef]

58. Copley, A.; McKenzie, D. Models of crustal flow in the India-Asia collision zone. Geophys. J. Int. 2007, 169, 683-698. [CrossRef]

59. Hilley, G.E.; Johnson, K.M.; Wang, M.; Shen, Z.K.; Burgmann, R. Earthquake-cycle deformation and fault slip rates in northern Tibet. Geology 2009, 37, 31-34. [CrossRef]

60. England, P.C.; Walker, R.T.; Fu, B.; Floyd, M.A. A bound on the viscosity of the Tibetan crust from the horizontality of palaeolake shorelines. Earth Planet. Sci. Lett. 2013, 375, 44-56. [CrossRef]

61. Zhang, C.; Cao, J.; Shi, Y. Studying the viscosity of lower crust of Qinghai-Tibet Plateau according to post-sesimic deformation. Sci. China Ser. D 2008, 38, 1250-1257.

(C) 2016 by the authors; licensee MDPI, Basel, Switzerland. This article is an open access article distributed under the terms and conditions of the Creative Commons Attribution (CC-BY) license (http://creativecommons.org/licenses/by/4.0/). 